\title{
Understanding structure, function, and mutations in the mitochondrial ATP synthase
}

\author{
Ting $\mathrm{Xu}^{1}$, Vijayakanth Pagadala ${ }^{2}$, David M. Mueller ${ }^{1, *}$ \\ ${ }^{1}$ Department of Biochemistry and Molecular Biology, The Chicago Medical School, Rosalind Franklin University of Medicine and Sci- \\ ence, 3333 Green Bay Road, North Chicago, IL 60064. \\ ${ }^{2}$ Department of Chemical Biology and Medicinal Chemistry, Eshelman School of Pharmacy, University of North Carolina, Chapel Hill, \\ NC. \\ * Corresponding Author: David M. Mueller, E-mail: david.mueller@rosalindfranklin.edu
}

\begin{abstract}
The mitochondrial ATP synthase is a multimeric enzyme complex with an overall molecular weight of about 600,000 Da. The ATP synthase is a molecular motor composed of two separable parts: $F_{1}$ and $F_{0}$. The $F_{1}$ portion contains the catalytic sites for ATP synthesis and protrudes into the mitochondrial matrix. $F_{0}$ forms a proton turbine that is embedded in the inner membrane and connected to the rotor of $F_{1}$. The flux of protons flowing down a potential gradient powers the rotation of the rotor driving the synthesis of ATP. Thus, the flow of protons though $F_{o}$ is coupled to the synthesis of ATP. This review will discuss the structure/function relationship in the ATP synthase as determined by biochemical, crystallographic, and genetic studies. An emphasis will be placed on linking the structure/function relationship with understanding how disease causing mutations or putative single nucleotide polymorphisms (SNPs) in genes encoding the subunits of the ATP synthase, will affect the function of the enzyme and the health of the individual. The review will start by summarizing the current understanding of the subunit composition of the enzyme and the role of the subunits followed by a discussion on known mutations and their effect on the activity of the ATP synthase. The review will conclude with a summary of mutations in genes encoding subunits of the ATP synthase that are known to be responsible for human disease, and a brief discussion on SNPs.
\end{abstract}

doi: $10.15698 /$ mic2015.04.197

Received originally: 16.12.2014;

in revised form: 04.03.2015,

Accepted 07.03.2015

Published 24.03.2015.

Keywords: ATP synthase, $F_{1}$ ATPase, $F_{1} F_{o} A T P$ synthase, mitochondrial diseases, petite mutations, uncoupling.

\section{Abbreviations:}

mgi - mitochondrial genome integrity, SNPS - single nucleotide polymorphisms.

\section{INTRODUCTION}

Peter Mitchell first proposed that the proton potential was used to provide the energy needed for the synthesis of ATP. While the chemiosmotic hypothesis [1] was proposed in 1961, because of the complexities of the enzyme, we are just now understanding the molecular details of ATP synthesis. The ATP synthase is a large multi-subunit enzyme complex composed of up to 20 different subunits or polypeptides that are in some cases present in multiple copies. The ATP synthase is bound to the inner membrane of the mitochondrion with a number of subunits being watersoluble while others are integral membrane proteins.

The mitochondrial ATP synthase is composed of two separable components: $F_{1}$ (factor 1 ) and $F_{0}$ (factor that confers sensitivity to oligomycin). The ATP synthase is a reversible molecular motor comprised of two parts: a proton turbine (within $\left.F_{0}\right)$ and a molecular machine $\left(F_{1}\right)$ that uses rotational energy to form ATP from ADP and phosphate. The proton turbine is powered by the flow of protons down a potential gradient across the mitochondrial membrane created by the electron transport chain during respiration. The rotor of the turbine is within the $F_{1}$ and when it rotates, drives the synthesis of ATP in the general mechanism described by the binding change hypothesis of Paul Boyer [2].

The ATP synthase acts to convert the energy of oxidation-reduction reactions of the electron transport chain (respiration) to the phosphorylation of ADP. The synthesis of ATP is "coupled" to the respiratory chain via the proton potential. The number of ATP molecules made, per number of atoms of oxygen reduced in the electron transport chain, ( $\mathrm{P} / \mathrm{O}$ ratio) is a measure of the coupling of ATP synthase with the electron transport chain [3]. The $\mathrm{P} / \mathrm{O}$ ratio is dependent upon a number variables, including the mem- 


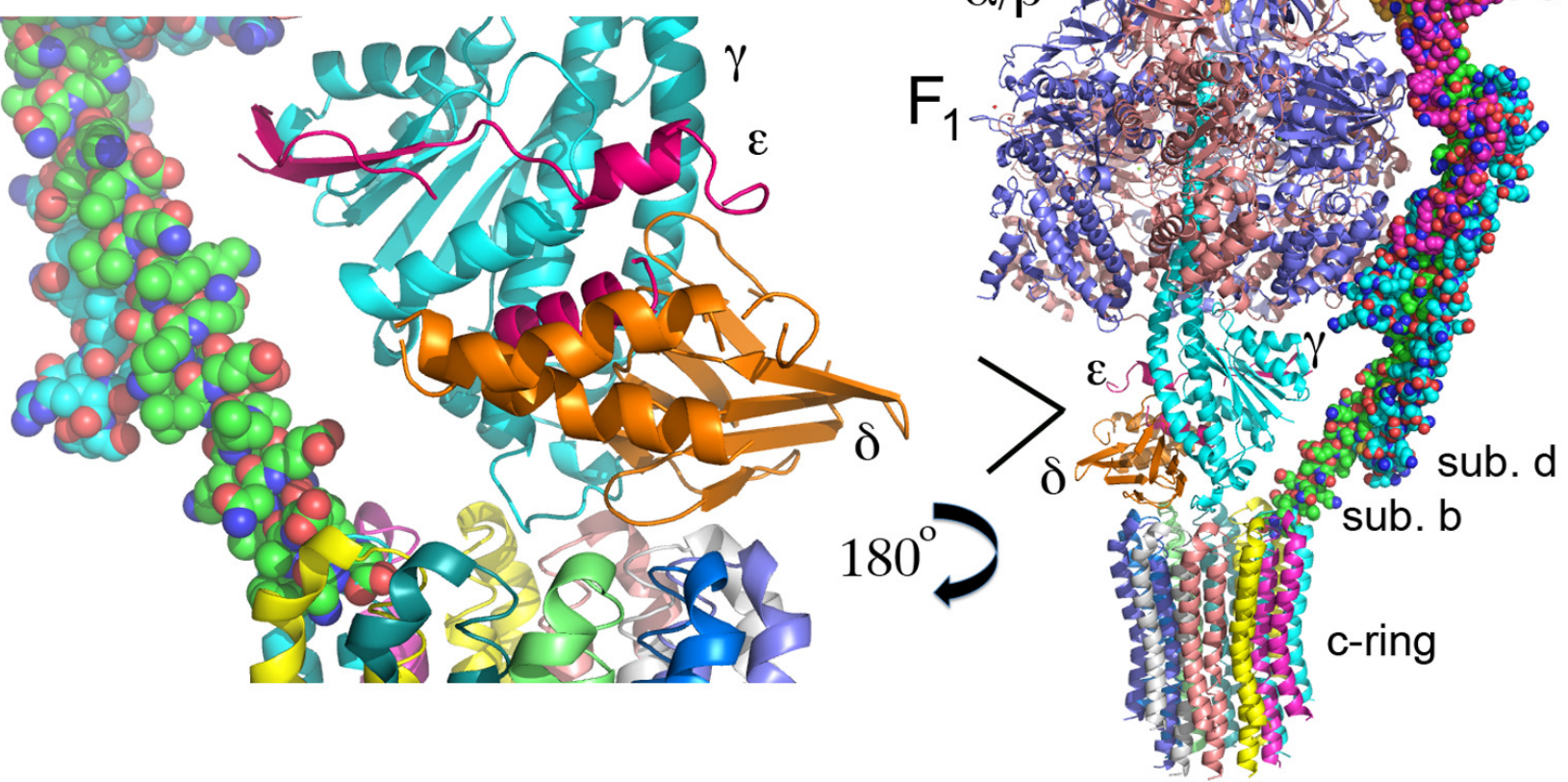

FIGURE 1: Structural representation of the ATP synthase. A composite representation of the ATP synthase is shown on the right with the $F_{1}$, subunits of the stator, and the $c_{10}$-ring shown. The structure of the $F_{1}$ and $c_{10}$-ring were derived from the $x$-ray crystal structures $(2 \mathrm{HDL}$ and $3 \mathrm{U} 2 \mathrm{~F}$ ) while the structures of the stator (peripheral stalk) were derived from the $\mathrm{x}$-ray crystal structures of the bovine components (2WSS and 2 CLY). Note, that a number of subunits have not been represented in the structure, most notably, subunit-a, which forms the proton half-channels.

brane integrity, site of the electron transport chain where the electrons are accepted, and the integrity of the ATP synthase. Because of these variables and basic experimental variations, a range of $\mathrm{P} / \mathrm{O}$ have been reported, but the consensus values for mammalian mitochondria, are 2.5 and 1.5 , for electrons entering at NADH dehydrogenase and succinate dehydrogenase, respectively $[4,5]$. The recent understandings of the structure/function relationship provide insight into the coupling capacity of the ATP synthase partly based upon the theoretical number of ATP molecules made per flux of protons. Using the c-ring stoichiometry of 8 (see discussion on $F_{0}$ below) for the bovine enzyme, the maximal theoretical $\mathrm{P} / \mathrm{O}$ ratio for mammalian mitochondria is 2.7 for NADH and 1.6 for succinate [3]. Yeast $S$. cerevisiae lacks the first coupling site [6] and considering the yeast c-ring stoichiometry of 10 , the $\mathrm{P} / \mathrm{O}$ ratio for NADH and succinate is about 1.3. However, for analysis of the ATP synthase function, given that all variables outside the ATP synthase are equal, a higher P/O ratio corresponds to a higher efficiency of the enzyme. Classical chemical uncouplers, such as 2,4 dinitrophenol, allow respiration without ATP synthesis thus reducing the $\mathrm{P} / \mathrm{O}$ ratio to zero, by dissipating the proton potential across the mitochondrial membrane. However, the flow of protons through $F_{o}$ into the matrix is also coupled - coupled to the phosphorylation of $A D P$, and mutations can alter the coupling which reduces the $\mathrm{P} / \mathrm{O}$ ratio.

\section{STRUCTURE AND ORGANIZATION OF THE $F_{1} F_{0}$ ATP SYNTHASE}

A composite model of the mitochondrial ATP synthase is shown in Figure 1. This composite model was derived from the crystal structure of the yeast $F_{1}$ ATPase (pdb: 2HLD, the yeast $\mathrm{c}_{10}$-ring, $3 \mathrm{U} 2 \mathrm{~F}$, and the bovine stator derived from two structures, 2WSS and 2CLY [7-11]). Table 1 lists the subunit composition of the bovine, yeast and $E$. coli enzymes along with the genes and relevant information on the structure/function relationship. The composite model is missing components of $\mathrm{F}_{0}$, which provide access for protons from the matrix and intermembrane space to the proton acceptor/donor site of the c-ring, which is positioned in the center of the lipid bilayer of the inner mitochondrial membrane. Based on subunit composition, the bacterial enzyme is much less complex than the mitochondrial enzyme, which may be due to the greater need for regulation in the eukaryotic cell. However, while the details differ, the general mechanism of ATP synthesis is conserved from the bacterial to the mammalian enzyme. The structure/function relationship of the subunits will be discussed in three groups: $F_{1}, F_{0}$, and stator. 
TABLE 1.

\begin{tabular}{|c|c|c|c|c|c|c|c|c|c|c|c|c|}
\hline $\begin{array}{l}\text { Mam- } \\
\text { malian }\end{array}$ & alias & E. coli & Yeast & $\#$ & Residues $^{+}$ & $\begin{array}{l}\text { MW } \\
\text { kD }\end{array}$ & $\begin{array}{l}\text { Yeast } \\
\text { Gene }\end{array}$ & $\begin{array}{l}\text { Human } \\
\text { Gene }\end{array}$ & Genome & Role & Sector & Importance \\
\hline$\alpha$ & sub. 1 & $\alpha$ & $\alpha$ & 3 & $510 m$ & 54.9 & ATP1 & ATP5A1 & nuclear & catalytic & $\mathrm{F}_{1}$ & Essential \\
\hline$\beta$ & sub. 2 & $\beta$ & $\beta$ & 3 & $478 m$ & 51.1 & ATP2 & ATP5B & nuclear & catalytic & $\mathrm{F}_{1}$ & Essential \\
\hline Y & sub. 3 & $\gamma$ & $\gamma$ & 1 & $278 m$ & 30.6 & ATP3 & ATP5C1 & nuclear & rotor & $\mathrm{F}_{1}$ & Essential \\
\hline$\delta$ & & $\varepsilon$ & $\delta$ & 1 & $138 m$ & 14.6 & $\begin{array}{l}\text { ATP16, } \\
\text { ATPס }\end{array}$ & ATP5D & nuclear & rotor & $\mathrm{F}_{1}$ & Essential \\
\hline$\varepsilon$ & & none & $\varepsilon$ & 1 & $61 \mathrm{~m}$ & 6.1 & $\begin{array}{l}\text { ATP15, } \\
\text { ATPE }\end{array}$ & ATP5E & nuclear & rotor & $\mathrm{F}_{1}$ & Important \\
\hline OSCP & sub. 5 & $\delta$ & OSCP & 1 & $195 \mathrm{~m}$ & 20.9 & ATP5 & ATP5O & nuclear & stator & & Essential \\
\hline sub. a & sub. 6 & sub. a & sub. a & 1 & 259 & 29.1 & ATP6 & ATP6 & mito & $\begin{array}{l}\text { proton } \\
\text { pore }\end{array}$ & $\mathrm{F}_{\mathrm{o}}$ & Essential \\
\hline sub. b & sub. 4 & sub. b & sub. b & 1 & $209 m$ & 23.3 & ATP4 & ATP5F1 & nuclear & stator & $\mathrm{F}_{\mathrm{o}}$ & Essential \\
\hline sub. c & sub. 9 & sub. c & sub. c & $\begin{array}{l}1 \\
0\end{array}$ & $\mathrm{f} 76$ & 7.76 & ATP9 & $\begin{array}{l}\text { ATP5G1, } \\
\text { ATP5G2, } \\
\text { ATP5G3 }\end{array}$ & $\begin{array}{l}\text { nuclear } \\
\text { (mammalian) } \\
\text { /mito (yeast) }\end{array}$ & $\begin{array}{l}\text { proton } \\
\text { pore }\end{array}$ & $F_{0}$ & Essential \\
\hline sub. 8 & $\mathrm{~A} 6 \mathrm{~L}$ & none & sub. 8 & 1 & $\mathrm{f} 48$ & 5.8 & ATP8 & ATP8 & mito & stator & $\mathrm{F}_{\mathrm{o}}$ & Essential \\
\hline sub. d & sub. 7 & none & sub. d & 1 & $173 m$ & 19.7 & ATP7 & ATP5H & nuclear & stator & $\mathrm{F}_{\mathrm{o}}$ & Essential \\
\hline sub. e & TIM11 & none & sub. e & 1 & ac95 & 10.7 & $\begin{array}{l}\text { ATP21/ } \\
\text { TIM11 }\end{array}$ & ATP5I & nuclear & stator & $\mathrm{F}_{\mathrm{o}}$ & Dispensable \\
\hline sub. $f$ & & none & sub. $f$ & 1 & $95 \mathrm{~m}$ & 10.6 & ATP17 & ATP5J2 & nuclear & stator & $\mathrm{F}_{\mathrm{o}}$ & Essential \\
\hline sub. g & & none & sub. g & 1 & $115 \mathrm{~m}$ & 12.9 & ATP20 & $\begin{array}{l}\text { ATP5L, } \\
\text { ATP5L2 }\end{array}$ & nuclear & stator & $\mathrm{F}_{\mathrm{o}}$ & Dispensable \\
\hline$?$ & sub. j & none & sub. i & 1 & $59 m$ & 6.7 & ATP18 & $?$ & nuclear & ?? & & Important \\
\hline$?$ & & none & sub. $k$ & 1 & $68 \mathrm{~m}$ & 7.5 & ATP19 & $?$ & nuclear & stator & & Dispensable \\
\hline F6 & & none & sub. $\mathrm{h}$ & 1 & $92 m$ & 10.4 & ATP14 & ATP5J & nuclear & stator & & Essential \\
\hline IF1 & & none & Inh1p & 1 & $63 \mathrm{~m}$ & 7.4 & INH1 & ATPIF1 & nuclear & regulatory & & Dispensable \\
\hline$?$ & & none & Stf1p & 1 & $63 m$ & 7.3 & STF1 & $?$ & nuclear & regulatory & & Dispensable \\
\hline$?$ & & none & Stf2p & 1 & 84 & 9.6 & STF2 & $?$ & nuclear & regulatory & & Dispensable \\
\hline
\end{tabular}

f: N-formyl Met, ac: putative acylation, m: mature; ${ }^{+}$The $\mathrm{N}$-terminus of the mature subunit was derived by many investigators, but a more comprehensive list by Arnold et al., [71].

\section{The $F_{1}$ ATPase}

The mitochondrial $F_{1}$ ATPase has the subunit composition $\alpha_{3} \beta_{3} \gamma \delta \varepsilon$. The molecular weight of the subunits are $55 \mathrm{kDa}$, $51 \mathrm{kDa}, 30 \mathrm{kDa}, 15 \mathrm{kDa}$, and $5.7 \mathrm{kDa}$ for the mature bovine $\alpha, \beta, \gamma, \delta$, and $\varepsilon$ subunits, respectively. The X-ray crystal structure of the bovine $F_{1}$-ATPase provided the first look at the structure/function relationship of the subunits in the $F_{1}$ ATPase [12] and subsequent structures, some with bound inhibitors, have given greater understanding into the molecular mechanism of ATP synthesis [13-23]. The $\alpha-$ and $\beta$-subunits share only about $20 \%$ identity but they form nearly identical folds and the $\alpha$-carbon atom positions differ only by about $2.8 \AA$ rmsd (root mean square deviation) with the greatest spatial divergence in the last 40 residues. The nucleotide binding sites are at the interfaces between the $\alpha$ - and $\beta$-subunits with the catalytic site formed primarily by the $\beta$-subunit and the non-catalytic site formed primarily by the $\alpha$-subunit. In accordance, there are 6 nucleotide-binding sites in the $\alpha_{3} \beta_{3} \gamma$ assembly with 3 being catalytic binding sites and 3 being noncatalytic binding sites. Support for the residues involved in the binding and catalysis deduced from the crystal structure was obtained by extensive mutagenesis of primarily the $E$. coli enzyme, prior to and after the structure determination (for review, see [24]). The P-loop (residues 156163 ) is integral to the catalytic site with $\beta$-subunit residues Gly161/Lys162/Thr163 being nearly invariable with only
Ser163 being a functional variant [25]. For ATP hydrolysis, $\beta$-Glu188 has been concluded to act as a catalytic base that activates a water molecule in a reaction mechanism that has been described as $S_{N} 2$ [26] where in the transition state, the $\gamma$-phosphate assumes a trigonal-bipyramidal arrangement of the oxygen atoms. ATP hydrolysis is the reverse of ATP synthesis and microscopic reversibility is widely accepted for this reaction. $\beta$-Asp256 and the $\beta$ - and $\gamma$-phosphates for ATP form the $\mathrm{Mg}^{2+}$ binding site. Arg373 of the $\alpha$-subunit is essential for catalysis and the crystal structure suggests that it is involved in stabilizing the penta-coordinate transition state. This role was more clearly demonstrated in the structure of the bovine $F_{1}$ ATPase with the transition state analogue, ADP:AlF ${ }_{4}$, which showed the guanidinium group of $\alpha$-Arg373 in a position to stabilize the transition state $[18,27]$. In the structure of the yeast $F_{1}$ ATPase, $\alpha$-Arg373 is also shown to participate in the binding of inorganic phosphate, one of the substrates for the synthesis of ATP [7].

The crystal structure of the $F_{1}$ gives clues as to why the non-catalytic sites are catalytically inactive. The relative position of the nucleotide bound in the catalytic and noncatalytic sites are nearly identical suggesting that the nucleotide-binding site is conserved. In the non-catalytic site, $\beta$-Arg356 is replaced by $\alpha$-Arg373, $\alpha$-Asp269 replaces $\beta$ Asp256, and $\alpha$-Gly174/ $\alpha$-Lys175/ $\alpha$-Thr176 are replaced by $\beta$-Gly161/ $\beta$-Lys162/ $\beta$-Thr163. However, $\beta$-Glu188 is re- 
placed by $\alpha-G \ln 208$ thereby removing the carboxylate that would otherwise act as a catalytic base. In addition, as will be discussed below, the structure of the catalytic sites alternate between a closed and open conformation during the catalytic cycle but all three of the non-catalytic sites are in the closed conformation. The absence of a catalytic base and the inability to transition between different catalytic conformations, as evidenced by the absence of open conformation, are major determinants in the catalytic incapacity of the non-catalytic sites.

The seminal $x$-ray structure of the bovine $F_{1}$ ATPase supported a rotational mechanism for ATP synthesis [12]. The three catalytic sites were different in both structure and occupancy; sites were occupied with AMP-PNP, ADP, and the third catalytic site had no bound nucleotide (empty). As such, the active sites were named, TP, DP, and E and the corresponding $\beta$-subunits were named, $\beta_{T P}, \beta_{D P}$ and $\beta_{E}$. The structure of the yeast $F_{1}$ ATPase showed very similar results but the DP site was occupied with AMP-PNP [7]. The structure of the nucleotide-binding site in $E$ was open and largely different from either DP or TP and this explained why no nucleotide was bound to $\beta_{\mathrm{E}}$. For instance, $\alpha$-Arg373 is displaced $7.2 \AA$ in the E site as compared to the TP or DP site and is not in position to interact with bound nucleotide. In the structure of the yeast $F_{1}$ ATPase, inorganic phosphate (or possibly sulfate) was bound in $\beta_{E}$ supporting the conclusion that $\beta_{\mathrm{E}}$ is a catalytically important state [7]. The asymmetry of the catalytic sites is determined by the position of the $y$-subunit, which is located in the center of the $\alpha_{3} \beta_{3}$ core. The structure suggested that the conformation of the catalytic site is determined by the position of the $\gamma$-subunit, which rotates relative to the $\alpha_{3} \beta_{3}$ core in $120^{\circ}$ increments during the catalytic cycle. Indeed, this was later proven by direct visualization of the move- ment of actin filaments fixed to the $\gamma$-subunit of bacterial $F_{1}$ ATPase due to hydrolysis and subsequently by demonstration of ATP synthesis driven by physical rotation of the rotor [28-30]. This mechanism was also consistent with the binding change site hypothesis for ATP synthesis proposed by Boyer [2]. Thus, the $\gamma$-subunit is a rotor that rotates within the $\alpha_{3} \beta_{3}$ catalytic core effecting conformational changes in the nucleotide binding sites thereby effecting ATP synthesis.

The molecular details of the motor movement of the synthetic pathway for ATP synthesis have been largely studied by determining the hydrolytic pathway with the assumption of microscopic reversibility. Single molecule experiments have mostly been done using the $\mathrm{F}_{1}$ from $\mathrm{Ba}$ cillus PS3 ([28, 31-40]) however, experiments using enzyme from E. coli, yeast, and human have also been reported [35, 37-41]. The results using $F_{1}$ from Bacillus, E. coli, and yeast generally agree, but the details of the mechanism differ slightly from that of the human enzyme. Figure $\mathbf{2}$ shows a molecular mechanism for the synthesis of ATP based on the studies for the hydrolysis of ATP by the bacterial and human enzymes [41] and also based on the structure of the bovine enzyme [12]. For the bacterial and yeast enzymes, there are 2 dwell positions during ATP hydrolysis, which can vary slightly: one at $0^{\circ}$, which corresponds to ATP binding and one at $80-90^{\circ}$ during the catalytic reaction. For the Bacillus PS3 enzyme, Pi release also occurs at $80^{\circ}$. For the human enzyme, there are 3 dwell positions during ATP hydrolysis: at $0^{\circ}$ due to ATP binding, at $65^{\circ}$ due to $\mathrm{Pi}$ release, and at $90^{\circ}$ due to ATP hydrolysis. The steps occur 3 times for a full rotation and thus each step is repeated in $120^{\circ}$ increments.

In terms of ATP synthesis for the human enzyme, at $0^{\circ}$, $F_{1}$ is proposed to contain ADP and $\mathrm{Pi}$ in one site and ATP in
A.

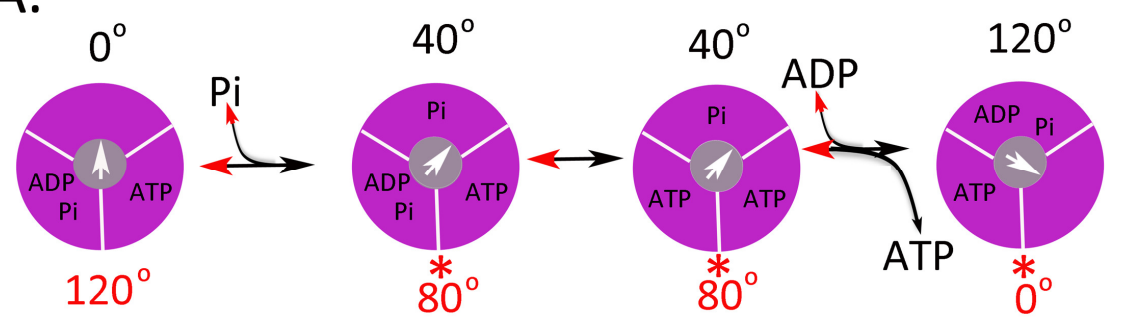

B.

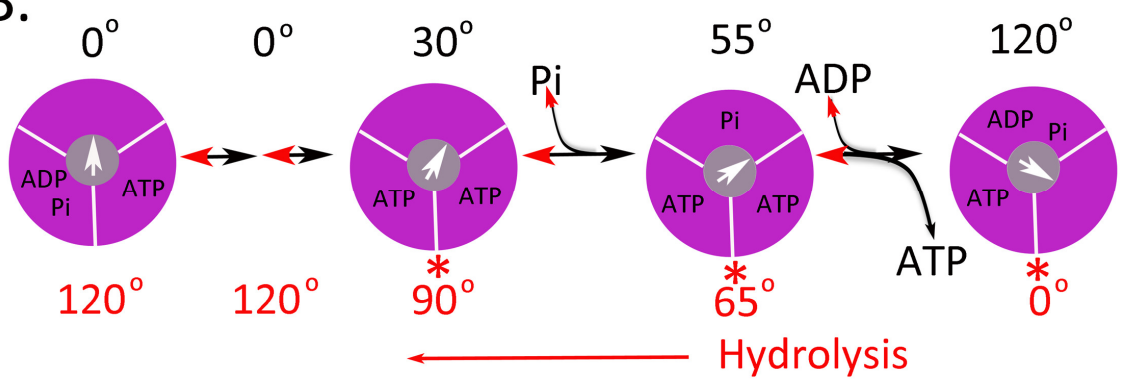

FIGURE 2: Possible scheme for site occupancy during ATP synthesis. Shown is the one possible mechanism for ATP synthesis based on the data for the bacterial [34] and yeast [35] enzyme (A) and the human (B) $F_{1}$ ATPase [41]. The direction from left to right is for ATP synthesis and right to left for ATP hydrolysis. The three binding sites are shown in magenta and the $\gamma$-subunit in grey with the arrow indicating the relative position. The asterisks $(*)$ indicate the dwell angle observed during ATP hydrolysis. 
a second site, while the third site is empty. The $y$-subunit rotates by $30^{\circ}$, which is followed by the phosphorylation of ADP to ATP. Pi binds to the empty subunit followed by the rotation of the $\gamma$-subunit by $25^{\circ}$. The final step consists of the binding of ADP, the rotation the $\gamma$-subunit by $65^{\circ}$ and the release of ATP made in a prior round. In this scheme, the newly bound ADP and Pi are not converted to ATP until the second round, and the newly formed ATP is not released until the third round. This mechanism fits nicely with the biochemical and structural properties of the enzyme. The three sites identified by crystallography of the bovine enzyme [12], TP, DP, and E sites, relate to the ground state structure likely at about $65^{\circ}$ in this scheme. The conversion of ADP and Pi to ATP has been shown to be isoenergetic by both $\mathrm{O}^{18}$ exchange studies and hydrolysis of ATP under unisite conditions [2, 42-45]. During ATP hydrolysis, there are 2 steps that provide torque: the release of $\mathrm{Pi}$ and ATP binding $[31,34,46]$. In the synthesis direction, energy would be needed for the binding of $\mathrm{Pi}$ and the release of ATP. In this scheme, all three sites are cooperating in the synthesis of ATP; one site is making ATP, the second site is binding ADP and $\mathrm{Pi}$, and the third site is releasing ATP.

This mechanistic scheme predicts that the inhibition of one of the three catalytic sites will completely inhibit the enzyme. To assess this, the Bacilus PS3 enzyme was prepared, containing 1,2 and $3 \beta$-subunits with the catalytic base mutation, $\beta$-E190Q [47]. ATPase activity of the enzyme with just one of three $\beta$-catalytic sites mutated was completely inhibited confirming that all three catalytic sites must be functional for activity. A similar study was done using mutations ("slow") in the $\beta$-subunit that reduced the binding constant for ATP to the catalytic site [48]. In this case, slowing the binding of ATP at one site had no effect on the rate of ATP binding at the other 2 sites. At a molecular level, the $\beta$-E1900 mutation acted in a dominant manner, while the "slow" mutations acted in a co-dominant manner. These results have implications in understanding the genetics of disease causing mutations in the $\alpha$ - and $\beta$ subunits of the ATP synthase.

The rotation of the $y$-subunit within the core of the $F_{1}$ ATPase causes the conversion of the conformation of the active site from E to DP to TP. There are 2 primary sites of interaction between the $\beta$-subunit, which largely forms the active site, and the $\gamma$-subunit, which forms the rotor and these regions are referred to as Catch 1 and Catch 2. Catch 1 includes residues in a loop formed by residues 312-319 in the $\beta$-subunit and residues in a helix of the $\gamma$-subunit formed by residues 252-255. Catch 2 encompasses residues within a loop from $387-398$ in the $\beta$-subunit and residues $87-90$ and $235-242$ in the $\gamma$-subunits [12].

The rotor, also called the central stalk, is composed of the $\gamma$-subunit along with the $\delta$ - and $\varepsilon$-subunits. The structures of the $\delta$ - and $\varepsilon$-subunits were not entirely visible in the first structure of the bovine $F_{1}$ ATPase but became clear in the structure of the bovine $F_{1}$ ATPase inhibited with $N, N^{\prime}$ dicyclohexylcarbodiimide (DCCD) [17]. The belief is that the inhibition by DCCD was incidental to the resolution of the $\delta$ - and $\varepsilon$-subunits and not causative. The $\delta$ - and $\varepsilon$-subunits are positioned at the base of the rotor and appear to sit close to the $F_{o}$ portion of the ATP synthase. As is discussed below, mutagenesis experiments suggest that the $\gamma^{-}, \delta$ - and $\varepsilon$-subunits share a common function in enzyme coupling - i.e., coupling proton translocation though $F_{0}$ with rotation of the rotor.

\section{Factor $F_{0}$}

Factor $F_{o}$ is also commonly referred to as $F_{0}$ ( $F$ zero). Efraim Racker named factor $F_{0}$ for the factor that conferred sensitivity of the $F_{1}$ ATPase to the antibiotic, oligomycin [49-51]. Oligomycin is now known to bind to subunit-c of $F_{o}$ and prevent proton flow. Recently, the structure of oligomycin bound to yeast subunit $\mathrm{c}$ has been determined by X-ray crystallography at $1.9 \AA$ resolution providing molecular details into oligomycin binding and an understanding of how oligomycin blocks proton translocation [52].

Based on the structural and genetic data, it is postulated that oligomycin binds on the face of the c-ring at the region comprised of the proton half channel, formed in part by subunit-a [52]. The $F_{o}$ sector is defined by the number of subunits in the biochemical preparation, all of which have the common characteristic of being membrane proteins or tightly associated with the membrane proteins. The $F_{o}$ portion of the ATP synthase comprises the proton turbine as well as the base of the stator, while the rotor is composed of $\gamma \delta \varepsilon$ [53]. The core of $F_{0}$ is composed of an oligomer of the c-subunits, which contain an essential carboxylate from the side chain of either a glutamate or aspartate residue. The side chain carboxyl acts as the proton donor and acceptor in proton translocation pathway. Two half-channels (or pathways) are postulated to exist and are thought to be formed by subunits-a, which provide access to the essential carboxylate on subunit-c and to the aqueous phase of the matrix and intermembrane spaces of the mitochondrion [54-56]. Other subunits, such as A6L, may either modulate or provide structural support for the $F_{0}$ portion of the enzyme. A recent model of the bovine ATP synthase using cryo-electron microscopy was able to show the arrangement of subunits $a, b, c, e, f, g$, and $A 6 L$, within the membrane domain [57].

The number of c-subunits varies between species with known stoichiometries ranging from 8-15 [3, 58-62]. Bovine $F_{o}$ is composed of a $c_{8}$-ring [3] while yeast $F_{o}$ is composed of a $\mathrm{C}_{10}$-ring $[8,58]$. The c-ring rotates within the membrane in steps determined by the number of csubunits in the c-ring. As such, movement of 8 protons are used to rotate the bovine c-ring $360^{\circ}$ driving the synthesis of 3 ATPs. This analysis provides insight into the thermodynamic considerations for ATP synthesis and provides theoretical values for $\mathrm{ATP} / \mathrm{H}^{+}$ratios and therefore, $\mathrm{P} / \mathrm{O}$ ratios [3].

The essential glutamate is located in the center of helix 2 of the c-ring subunit, which positions it in the middle of the lipid bilayer. Thermodynamic considerations suggest that only the protonated form of glutamate is able to exist in the center of the bilayer and protonation/deprotonation reaction must occur in a hydrophilic environment created by two half-channels. The half-channels provide access to 
either the matrix or the intermembrane space thereby allowing proton flow between the compartments. The halfchannels are thought to be comprised of subunit-a, but may also include subunit $b$ and other components of $F_{0}$. There is only one strictly conserved residue in subunit-a, Arg210 (E. coli numbering, Arg259, human), which is believed to be a principle component in the proton translocation pathway (see [63] for review). Recent electron microscopy images of the Thermus thermophilis V-ATPase and the bovine ATP synthase suggest that the contact between $F_{0}$ and the half-channel is surprisingly small $[57,64]$. This loose association may be essential for the high-speed rotation of the c-ring.

\section{The stator}

The stator is also referred to as the peripheral or extrinsic stalk. The stator functions to hold $F_{1}$ fixed to allow rotation of the rotor within the core of $F_{1}$. The stator provides a structural support and is not involved directly in the catalytic reaction. The stator is composed of the oligomycin sensitive conferring protein (OSCP, subunit 5 ), subunit $b$, subunit $d$, and F6 and the X-ray structure has been solved for the peripheral stalk of bovine enzyme $[9,11]$. Subunit $b$ is anchored to the membrane while OSCP is locked to the top of $F_{1}$. (The naming of subunit 5 as OSCP is unfortunate since OSCP does not participate in forming the oligomycinbinding site.) OSCP was so named because oligomycin prevents proton flow through $F_{0}$ and inhibits ATP hydrolysis only if $F_{1}$ is functionally attached and coupled to proton movement. Breaking the stator uncouples ATP hydrolysis from proton translocation because the $F_{1}$ core can spin instead of the rotor. The primary structure of the stator proteins shows low conservation between bovine and yeast, as evidenced by yeast subunit $h$ and bovine $F 6$, which have just $14.5 \%$ sequence identity. However, the function is conserved because expression of a cDNA encoding bovine $\mathrm{F} 6$ complements the deletion mutation of the gene encoding subunit $h$ in yeast [65].

\section{Other subunits}

Subunit $f$ is a component of the bovine and yeast ATP synthase $[53,66,67]$, however, the role is uncertain. Subunit $f$ associates with $F_{0}$ and deletion of the gene in yeast results in phenotypes that are typical for an ATP synthase that is uncoupled [67] (see below). The role of subunit $f$ is still ambiguous as loss of either a component of the peripheral stalk or $F_{0}$ give similar phenotypes. Yeast with a null mutation in the corresponding gene is unable to grow on a nonfermentable carbon source and loses mitochondrial DNA at a high rate [67]. As such, subunit $f$ is an essential component of the mitochondrial ATP synthase.

Subunit i (aka subunit j) was identified as a component of the yeast ATP synthase nearly coincidently by two laboratories, which is why it has an alias $[68,69]$. A mammalian homologue for subunit $i$ has not been identified though this does not exclude its presence. Subunit i easily dissociates from the ATP synthase complex, which explains why it had not been identified in prior studies. Deletion of the gene encoding subunit $i$ gave different results in the two laboratories. In one case, deletion of the gene encoding yeast subunit i does not alter the assembly of the ATP synthase; the resulting ATP synthase is functional, but is less well coupled based on the $\mathrm{P} / \mathrm{O}$ ratio and growth phenotype of the yeast [68]. However, in the second laboratory, deletion of the gene encoding subunit i resulted in complete loss of the ATP synthase with absence of the mitochondrial encoded subunits [69]. These results are not as different as they appear because, a loss of coupling of the ATP synthase will result in the loss of mitochondrial DNA [70]. As such, these results differ by a matter of degree, which can be caused by different growth conditions or genetic background of the yeast strains. While the role of subunit $i$ is uncertain, it does appear to provide a role in the efficient coupling of the yeast ATP synthase.

A dimer form of the ATP synthase has been shown in yeast [71] and there is evidence of dimer forms of the ATP synthase in bovine, chloroplast, and other species of fungi $[72,73]$. The dimer form appears to be involved in formation of cristae of the inner mitochondrial membrane, which may be why the dimer form has not been shown for the bacterial enzyme $[74,75]$. Subunits e, $k$, and g are selectively associated but only subunits e and $g$ are necessary for dimer formation $[71,75]$. Subunit $k$ has not been identified in the mammalian ATP synthase although this does not exclude the possibility of a mammalian homolog. Deletion of the gene encoding subunits e or $\mathrm{g}$ has pleiotropic effects including a decrease of cytochrome oxidase activity [76, 77]. While it is not uncommon for mutations in genes encoding mitochondrial proteins to exhibit pleiotropic effects, this effect was unusual in that the levels of cytochromes a $+a_{3}, c+c_{1}$, and $b$ were unaltered suggesting that activity could be altered without altering synthesis or stability of the cytochromes. This and an unrelated study [78] suggest a link, which will be discussed later, between the ATP synthase and the respiratory chain.

The natural inhibitor protein, IF1, is thought to regulate the ATPase activity of the ATP synthase [79]. The inhibitor protein has a unique characteristic in that it inhibits ATP hydrolysis, but not ATP synthesis. In yeast, there are also related molecules, Stf1p and Stf2p. Stf1p appears to stabilize the interaction of IF1 with $F_{1}$ or possibly is an isoform of IF1 [80]. Deletion of the gene encoding IF1 from yeast results in mitochondria that demonstrate uncontrolled hydrolysis of ATP in the presence of a chemical uncoupler such as 2,4 dinitrophenol [81]. A number of studies have suggested that inhibitor protein has a role in preventing hydrolysis of ATP under ischemic conditions in mammalian heart [82-86] and other metabolic effects [87]. While this is a conceptually attractive hypothesis, the energy of the hydrolysis of ATP by the ATP synthase is not lost - it is coupled to the pumping of protons across the mitochondrial membrane creating a proton gradient. In contrast, the hydrolysis of ATP by free $F_{1}$ ATPase is futile and wasteful, and it would be important for the cell to control this hydrolysis. Free $F_{1}$ ATPase has been suggested to be an intermediate in the assembly pathway of the ATP synthase [88]. Thus, IF1 may serve a role in preventing the hydrolysis of ATP by free $F_{1}$ that occurs during biogenesis of the ATP synthase 
complex. Stf2p appears to be important in yeast during times of stress or dehydration [89]. Interestingly, overexpression of Stf2p in yeast results in a reduction of reactive oxygen species (ROS) in response to stress and thus provides a possible target to reduce ROS production in humans. In this regard, IF1 has been shown to be important for the survival of HeLa cells when they are exposed to high concentrations of ROS, but IF1 is not important for cell survival under normal conditions [90].

The X-ray crystal structure of the bovine inhibitor protein bound to the bovine $F_{1}$ ATPase has shown that IF1 is trapped between the pair of the $\alpha$ - and $\beta$-subunits, which form the DP site $[91,92]$. The mechanism of inhibition of IF1 was described in terms of the binding change hypothesis, but the explanation will be given in terms of the nomenclature used for the active sites of the ATP synthase. IF1 is postulated to initially bind to the open site (E), which closes to form the TP:IF1 site during ATP hydrolysis. A second round of ATP binding and hydrolysis converts the TP:IF1 site to the DP:IF1 site where it is locked in the final inhibited form. IF1 is thought to prevent the conversion of the DP:IF1 site to the E:IF1 site by steric interference within the interface of the $\alpha$ - and $\beta$-subunits. The reason as to why IF1 is unable to inhibit the reverse reaction, ATP synthesis, is still uncertain. The structural studies [91] do not support its role as a ratchet, which has been proposed for the inhibitory mechanism of the bacterial $\varepsilon$-subunit [93]. The trivial explanation is that the conditions, such as $\mathrm{pH}$ and $\Delta \Psi$, during ATP synthase differ from conditions under which ATP hydrolysis occur, and IF1 does not bind to $F_{1}$ under synthesis conditions.

\section{Deletion of genes encoding $F_{1}$ subunits in yeast}

A mutation that completely eliminates expression of a gene - a null mutation - is the simplest mutation to understand both at the level of the structure/function relationship of the protein and in relation to clinical relevance of the mutation. However, there are at least 2 instances with added clinical relevance and understanding of structure/function of the protein of the null mutation. First, haploinsufficiency is the situation where loss of one of the wild type alleles in a diploid organism causes a disease. Thus, a $50 \%$ drop in expression level is sufficient to cause disease or defective phenotype. Second is the situation where a null mutation causes a dominant negative or gain of (dysfunctional) activity. Both of these cases appear to be applicable in the yeast model system of null mutations in genes encoding subunits of the ATP synthase as well as for the yeast vacuolar ATPase $[94,95]$.

All five subunits of the mitochondrial $F_{1}$ ATPase are essential for the function of the ATP synthase. A priori, it would be predicted that deletion of any one of the five genes encoding the subunits of $F_{1}$ would result in similar, if not identical, phenotypes. However, the situation is much more complicated than predicted [70]. The phenotypes of the yeast strain with a deletion mutation in either the gene encoding $\alpha$ or $\beta$, were typical and not surprising; the cells were defective in oxidative phosphorylation and did not grow on medium with a nonfermentable carbon source.
Different from the phenotypes caused by loss of $\alpha$ or $\beta$, yeast cells with a deletion of the gene encoding $\gamma$ result in very small colonies and the cells had completely lost their intact mitochondrial DNA, i.e., cytoplasmic petite $\left(\rho^{-} / \rho^{0}\right)$. However, deletion of genes encoding $\alpha$ and $\gamma(\Delta \alpha \Delta \gamma)$ in the same cell results in cells with a phenotype that is similar to that of yeast with a deletion mutation just in the gene encoding $\alpha(\Delta \alpha)$. Similarly, cells with a deletion mutation in the gene encoding $\beta$ had the same phenotype as cells with double mutation, $\Delta \beta \Delta \psi$. Deletion of the gene encoding $\delta$ from yeast resulted in a phenotype that was similar to those obtained with deletion of the gene encoding $\gamma$, but not as dramatic. Similar to cells that have a deletion in the gene encoding the $\gamma$-subunit, cells with a deletion of the gene encoding $\delta$ caused the cells to lose $100 \%$ of their intact mitochondrial DNA. Lastly, deletion of the gene encoding $\varepsilon$ had the weakest effect on the phenotype, but $60 \%$ of the cells became cytoplasmically petite. In each case, the percentage of cells that became cytoplasmically petite returned to normal level when a null mutation in the gene encoding either $\alpha$ or $\beta$ was added. This effect indicates that the phenotype caused by the deletion of the gene encoding either $\alpha$ or $\beta$, was epistatic to that caused by deletion of the gene encoding either the $\psi, \delta$ or $\varepsilon$-subunit.

Mutations in genes encoding chaperones, ATP11 or ATP12, had the same epistatic effect, in respect to mutations in the genes encoding the $\gamma^{-}, \delta-$, and $\varepsilon$-subunits, as deletion mutations in the genes encoding $\alpha$ or $\beta$. Atp11p and Atp $12 p$ are needed for the assembly of the $\alpha$ - and $\beta$ subunits into $F_{1}$ and yeast strains with mutations in either ATP11 or ATP12 have phenotypes similar to yeast strains with mutations in the genes encoding the $\alpha$ and $\beta$-subunits [96-101]. A reasonable explanation for the effect was that a subcomplex of the ATP synthase could assemble without one of the rotor subunits, but not without $\alpha$ or $\beta$, and the subcomplexes devoid of a rotor subunit were responsible for the additional phenotypes.

The effect by the loss of a subunit in the rotor can be deduced after considering the role of the rotor. With loss of the rotor, one would predict that the $F_{1} F_{0}$ subcomplex would allow protons to flow through $F_{o}$ without $F_{0}$ being coupled to the rotation of the rotor. Under this condition, the enzyme would be completely uncoupled and the mitochondria would exhibit a $\mathrm{P} / \mathrm{O}$ ratio of zero. However, cells lacking $\gamma$ or $\delta$ become $100 \%$ cytoplasmically petite. Since $F_{0}$ subunits are encoded in the mitochondrial DNA, it is impossible to assess defects in coupling when the strain becomes entirely petite. Two different approaches helped resolve this problem. First, diploid yeast cells that were heterozygote for a mutation in the gene encoding $\gamma$ or $\delta$ were impaired, but not totally defective in oxidative phosphorylation. Analysis of mitochondria isolated from these strains indicated that the deletion mutations caused an uncoupling of the ATP synthase presumably due to a leakage of protons into the mitochondria via the uncoupled ATP synthase subcomplex [102]. The second approach used a doxycycline-regulated expression system to gradually reduce the level of $\delta$ in the cell [103]. Using this system, direct evidence was obtained that the ATP synthase could 
assemble in the absence of $\delta$ and that this $\delta$-less ATP synthase subcomplex was uncoupled because of a $F_{o}$ mediated proton leak.

A central question that was left unanswered in this study was the relationship between uncoupling and loss of mitochondrial DNA, i.e. cytoplasmic petite formation. While this has not been conclusively answered, there is a reasonable explanation that is consistent with what is known about mitochondrion biogenesis [104]. The biogenesis of the mitochondrion is dependent on the import and processing of proteins that are encoded in the nucleus and made in the cytoplasm. The import of the mitochondrial precursor proteins from the cytoplasm into the mitochondrion is dependent on proton potential across the mitochondrial membrane $[105,106]$. (In petite strains or under anaerobic conditions, the mitochondrial membrane potential is generated by the electrogenic exchange of cytoplasmic $A T P^{4-}$ with matrix $A D P^{3-}$ [107-109].) As such, uncoupling of the mitochondrial membrane will prevent the import of newly synthesized proteins and thus inhibit mitochondrion biogenesis. While yeast is a facultative anaerobe and able to survive without oxidative phosphorylation, all eukaryotic cells require mitochondrion and thus inhibiting the biogenesis is lethal. If the ATP synthase is uncoupled, the cell can only survive if the proton leak is blocked and that is most easily achieved in yeast by eliminating the mitochondrial DNA, which encodes subunits a, c and 8 which comprise the proton pathway. Thus, there is a correlation between the degree of uncoupling of the ATP synthase and the propensity of the cells to become cytoplasmic petite.

The cellular phenotypes and biochemical consequences associated with deletion of genes encoding $\alpha, \beta, \gamma, \delta$, and $\varepsilon$ provided key insights into role of the $\delta$ and $\varepsilon$ subunits in the coupling of the enzyme. The deletion mutations in the genes encoding the $\gamma, \delta$, or $\varepsilon$ subunits resulted in an enzyme that was uncoupled and as such, provides a basis for recognizing missense mutations that uncouple the ATP synthase. Even the loss of a single copy of the genes encoding the $\gamma$ or $\delta$-subunits in a diploid strain can result in a dysfunctional uncoupling activity, i.e., haploinsufficiency [102].

The mitochondrial $\varepsilon$-subunit is unique in that it is the only $F_{1}$ subunit for which there is no bacterial homolog. As with deletion of the gene encoding subunit $i$, deletion of the yeast gene encoding $\varepsilon$ has given different phenotypes depending on the laboratories; in one case the loss of $\varepsilon$ inactivated the enzyme while in the other case, its loss severely compromised the enzyme based on the growth phenotype on a non-fermentable carbon source $[110,111]$. This discrepancy has been apparently resolved by the identification of selective mutations in the genes encoding either subunit a and c, which suppressed the growth phenotype in the yeast strain with the null mutation in the gene encoding the $\varepsilon$-subunit [112]. It was suggested that the strains with a null mutation in the gene encoding the $\varepsilon$ subunit that were able to grow on a nonfermentable carbon source, had picked up a suppressor mutation in either the gene encoding subunit a or $\mathrm{c}$.

\section{Missense mutations that uncouple the ATP synthase}

The coupling of the ATP synthase is defined here as the coupling of ATP synthesis or hydrolysis with the movement or pumping of protons. Mutations that inhibit activity of the ATP synthase can act either by inhibiting the enzymatic reaction, as in an active site mutation, or by uncoupling proton movement with the reaction cycle. The coupling of rotation of the rotor with flow of proton and the synthesis of ATP is an intricate mechanism caused by numerous inter-subunit contacts. As such, mutations exist that alter these interactions and affect coupling. A genetic selection scheme, seemingly unrelated to the ATP synthase, selected cells with mutations in genes encoding the ATP synthase and these mutations cause an uncoupling of the ATP synthase.

Cytoplasmic "petite" yeast strains have either lost large parts of, or completely lost their mitochondrial DNA, rendering the yeast incompetent for synthesis of mitochondrial encoded proteins. The yeast, Kluyveromyces lactis, is a facultative anaerobe like Saccharomyces cerevisiae, but differs in that it requires mitochondrial DNA even when grown on a fermentable carbon source. Based on this phenotype, the cells are referred to as being "petite negative". This is in contrast to $S$. cerevisiae, which is petite positive as deletions in the mitochondrial DNA are not lethal. Mutations in $K$. lactis were identified that convert the cells from petite negative to petite positive and the complementation group was named mitochondrial genome integrity (mgi) [113-118]. Surprisingly, the mgi mutations mapped in the genes encoding $\alpha-, \beta-$, and $\gamma$-subunits of the mitochondrial ATP synthase. The yme1 mutation converts $S$. cerevisiae from petite positive to petite negative. A number of mutations were isolated from a yme1 $\mathrm{S}$. cerevisiae strain that converted the yeast from petite negative, back to petite positive $[119,120]$. These mutations also mapped to the genes encoding the ATP synthase with some of them being identical to mgi mutations identified in $K$. lactis. In a manner analogous to $K$. lactis, the survival of the blood stream form of Trypanosoma brucei requires mitochondrial gene expression despite the absence of oxidative phosphorylation during this stage of the life cycle. However, a single polymorphism in the gene encoding the $\gamma$-subunit, which mapped in the same region as the mgi mutations in the gene encoding the $\gamma$-subunit, was identified that allowed for dyskinetoplasty (lack of mitochondrial DNA) in T. brucei. $[121,122]$. These diverse systems converging on common mutations, suggest a shared mechanism linking the ATP synthase with loss or retention of mitochondrial DNA.

Mutations analogous to mgi mutations were made in yeast $S$. cerevisiae and the biochemistry and structure of the enzyme was studied [123]. S. cerevisiae is petite positive and when mgi mutations are introduced into this yeast there is a striking increase in the percentage of petite strains during normal division. A variety of biochemical studies on the isolated mitochondria indicated that the $m g i$ mutations caused an uncoupling of the ATP synthase presumably caused by proton leakage through $F_{0}$. Mapping the mutations on the structure of the yeast $F_{1}$ ATPase indicated that the mutations clustered in two regions of the $F_{1}$ 


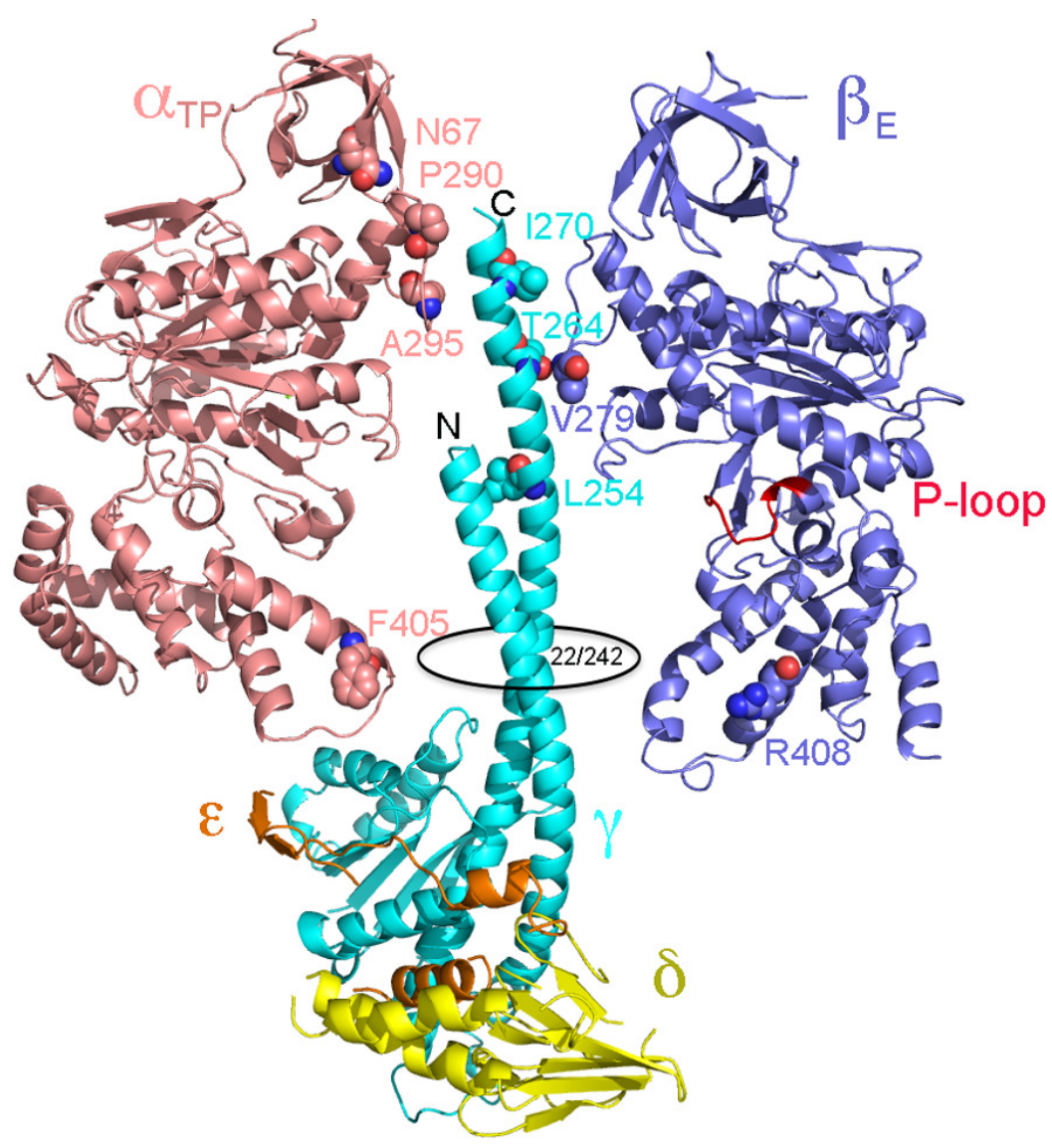

FIGURE 3: Location of residues in the yeast ATP synthase classified as mgi. The structural representation is derived from the $\mathrm{x}$-ray structure of the yeast $F_{1}$ ATPase (2HDL). Shown are the $\alpha \beta \gamma \delta \varepsilon$ subunits, as indicated. The $\alpha_{3} \beta_{3}$ core has been stripped down to a single $\alpha$ and $\beta$ subunit to simplify the view. The $m g i$ residues are as labeled. The $\mathrm{N}$ - and $\mathrm{C}$ - terminal ends of the $\mathrm{\gamma}$-subunit are indicated as is the region of the orifice of the $\alpha_{3} \beta_{3}$ assembly, which is located at residues 22 and 242 of the yeast $\gamma$-subunit. The nucleotide binding Ploop domain is colored red and labeled.
ATPase - along the collar region, which steadies the rotation of the central stalk and in the region first identified in bovine $F_{1}$ ATPase and referred to as Catch 2 region [12] in the $\beta$-subunit which interacts with the $\gamma$-subunit (Figure 3 ) [123]. X-ray crystallography of some of the mutant structures provided a structural basis for the mechanism of uncoupling rotation of the rotor from ATP hydrolysis or synthesis [124]. Interesting, two of the mgi mutations ( $\alpha$ Asn67lle and $\beta$-Val279Phe) appear to disrupt phosphate binding to the $E$ site which, if correct, would suggest that these mutations allow for proton driven rotation in the absence of substrate (phosphate) being bound thereby resulting in a less efficient, less coupled, enzyme.

While the structural and biochemical studies gave an insight into the effect of mgi mutations on the biochemistry of the ATP synthase, it is still not clear how the mutations convert a petite negative strain into a petite positive strain. There is a correlation between the percentage of petite mutations formed and the severity of the mutation on the coupling of the ATP synthase, but this is distinct from how uncoupling allows the petite negative cells to lose their mitochondrial DNA.

\section{Mutations in the $\boldsymbol{\gamma}$-subunit}

The coiled-coil motif formed by the $\mathrm{N}$ - and $\mathrm{C}$-terminal helices of the $\gamma$-subunit, rotates within the $\alpha_{3} \beta_{3}$ complex. The rotation is believed to proceed with minimal resistance but maintains critical interactions to cause catalysis. Tethering the $\gamma$-subunit to the residues on either the $\alpha$ - or $\beta$-subunits inhibits rotation and blocks catalysis. When disulfide bridges were introduced in the $E$. coli ATPase between $\gamma$ Leu262Cys and $\alpha$-Ala334Cys or between $\gamma$-Cys 87 to $\beta$ Asp380Cys, the ATPase driven rotation was nearly completely inhibited [125]. However, rotation was not blocked when a covalent cross-link was made between $\gamma$-Ala285Cys and $\alpha$-Pro280Cys. The location of the cross-links apparently provides an explanation to resolve this paradox. The cross links to $y$-Leu262Cys and $y$-Cys87 were positioned in the center or below the center of the rotor while the cross-link to $\mathrm{y}$-Ala285Cys was positioned at the top of the rotor. This study suggested that the amino acid residues at the top of the rotor could swivel along the $c-\alpha$ bonds or around the side chain bonds $[126,127]$.

There are two isoforms of the $\gamma$-subunit in humans and other mammals: a "heart isoform" and a "liver isoform". The isoforms differ by a single amino acid; the liver isoform has an additional residue, an aspartate, at the C-terminus. The isoforms are formed by alternative splicing, which is conserved and highly regulated [128-131]. The heart isoform is expressed in heart, skeletal muscle, and intercostal muscle, diaphragm, all containing tissues with a high and variable energy demand. The liver isoform is expressed in brain, thyroid, spleen, pancreas, kidney, testis and liver. Of these, all but the brain consume relatively low amount of ATP and have a steady energy demand [132]. The expecta- 
tion is that these isoforms have biochemical significance and are important for the physiology of the tissues.

Based on the crystal structures of the bovine and yeast $\mathrm{F}_{1}$, we can predict that the Asp at the C-terminus of the $\gamma$ subunit in the liver isoform forms a salt linkage with $\alpha$ Arg288. However, comparison of the ATPase activity of the two isoforms by both bulk ATPase activity measurements and analysis of rotation of single molecules did not demonstrate any significant difference in kinetics of ATPase reaction cycle $[35,133]$. This suggests that if the isoforms serve as a regulatory mechanism, that the regulation must occur in conjunction with another molecule.

Earlier studies on the bacterial enzyme have been critical in understanding the structure-function relationship of the $y$-subunit of the ATP synthase. The "axle" of the bacterial and mitochondrial enzymes extends for about 22 residues on the $\mathrm{N}$-terminus and for about 43 residues on the C-terminus (Figure 3 ). The helices formed by these regions form a coiled-coil that spins within the center of the $\alpha_{3} \beta_{3}$ assembly. An early mutation isolated in $E$. coli $\gamma$-subunit gene, NR70, resulted in a 7 amino acid deletion, residues $22-28$, in the bacterial $y$-subunit $[134,135]$. The resultant bacteria were lacking membrane bound $F_{1} F_{o}$ and exhibited a reduced ability to accumulate sugars and amino acids but this could be restored by the addition DCCD, a covalent inhibitor of $F_{0}$. [134, 135]. DCCD is apparently acting to prevent proton leakage through $\mathrm{F}_{\mathrm{o}}$. As such, this mutation exhibited qualities that are predicted for mutations that uncouple the ATP synthase, which allow free movement of protons.

A number of other studies have more closely defined the structure function relationship of the bacterial $\gamma$ subunit. Despite deletion of the axle region of the $y$ subunit (the coiled-coil helices) the enzyme was still able to rotate in the correct direction with ATP hydrolysis. Howev$\mathrm{er}$, the rotation rate was greatly reduced and mutants with large deletions exhibited irregular motion [136]. Another study demonstrated that major deletions in the axle impaired ATP synthesis only by about 75\% [137]. Based on the results from these and other studies, it was concluded that the C-terminal region of the $\mathrm{y}$-subunit is responsible for about half of the torque generated by ATP hydrolysis and the difference attributable to the interactions between the $\gamma$-subunit and residues at the orifice of the $\alpha_{3} \beta_{3}$ subcomplex [138-140]. These results are also consistent with the location of the mgi mutations, which map at the top of the area surrounding the axle and at the general area of the orifice of the $\alpha_{3} \beta_{3}$ subcomplex (Figure 3).

\section{MUTATIONS IN THE ATP SYNTHASE THAT CAUSE HUMAN DISEASE}

\section{Disease-causing mutations in the nuclear DNA}

There have been three reports of mutations in nuclear genes encoding subunits of the ATP synthase causing human disease: that encoding the $\varepsilon$-subunit [141] and more recently, the $\alpha$-subunit $[142,143]$. In the first case, the mutation Tyr11 of the mature $\varepsilon$-subunit (Tyr12 in the precursor) was mutated to a Cys. Tyr11 is highly conserved in the $\varepsilon$-subunit in which the primary sequence is otherwise poorly conserved. The $\varepsilon$-subunit forms a two-helix hairpin and the $\mathrm{N}$-terminus interacts with both the $\gamma$ - and $\delta$ subunits of the $F_{1}$ ATPase. The side-chain phenolic group of Tyr11 is in the center of a pocket formed by residues (based on the structure of the bovine $F_{1}$ ATPase, pdb: $1 E 79$ [17]) Trp4, Ser10, Ile12, Arg13, Tyr14, and Ser15 of the $\varepsilon$ subunit, Val57, Leu58, Ser79 and Gly80 of the $\delta$-subunit, and Asn203 and Glu206 of the $\gamma$-subunit. The mutation, $\varepsilon$ Tyr11Cys, resulted in a low level of the intact ATP synthase in the fibroblast cells of the patient, but there was an apparent associated increase in the level and activity of Complex III and IV of the electron transport chain. The ATP synthase that was assembled had reduced amount of associated $\varepsilon$-subunit, but nonetheless, was apparently functional. The patient was a 22 year old that presented with symptoms typical of a patient with a mitochondrial disease. This disease is not lethal and thus consistent with the impairment, but not elimination, of activity of the ATP synthase. The mutation likely alters the assembly of the intact ATP synthase.

The second example of a nuclear mutation in the ATP synthase causing a human disease was in the $\alpha$-subunit, Tyr278Cys (Tyr321Cys of the pre-protein) [142]. In this case, the patient had symptoms that were typical of a severe mitochondrial disease resulting in death of the child at age 3. The patient had one sister with similar symptoms who died at 15 months. Both patients paradoxically had combined respiratory chain deficiency. Despite more severe symptoms and outcome, the Tyr278Cys mutation had a much less apparent effect on the function of the ATP synthase. The most pronounced effect of the mutations was observed in both the muscle and liver of the patient, where there was a moderate depletion of the mitochondrial DNA. A similar finding was observed when the comparable mutation was modeled in yeast [142]. Tyr278 is within the region where the mgi mutations were clustered in the yeast $F_{1}$ ATPase suggesting that the mutation might affect the coupling capacity. The increased loss of mitochondrial DNA is also consistent with the mgi phenotype and thereby suggesting that the mutation might decrease the coupling of the ATP synthase. However, while there was some indication that the corresponding mutation when made in yeast uncoupled the mitochondrial ATP synthase, the effect was not large. One possible explanation for this paradox is that even mild uncoupling of the ATP synthase causes loss of mitochondrial DNA over many generations, acting analogous to a degenerative disease, and the loss in the mitochondrial DNA is ultimately the reason for the disease symptoms.

The third example was a disease presented in two siblings who contained a mutation in the $\alpha$-subunit, Arg286Cys (Arg329 in the pre-protein) [143]. Both children died in the first weeks of life due to severe encephalopathy with associated extensive cerebral damage. In addition, there was damage to the lungs, kidney, and skeletal muscle. The mutation caused a dramatic decrease in the cellular level of the ATP synthase as measured by activity. The mutation was inherited from the father who was a heterozy- 
gote carrier. The mother did not have the effecting mutation but apparently had another mutation that caused loss of expression of the gene encoding the $\alpha$-subunit from one of her homologs. Consistent with this, the level of mRNA for the $\alpha$-subunit was decreased by $40 \%$ in the blood cells from the mother as compared to the father. As such, both patients were heterozygous for the Arg286Cys causing mutation and did not express any wild type form of the $\alpha$ subunit. Complementation studies using cells derived from the patients indicated that the mutation in the gene encoding the $\alpha$-subunit was responsible for the cellular defects. Unlike the mutation discussed earlier, this mutation did not have any apparent pleiotropic effect on the level of mitochondrial DNA or complexes of the electron transport chain.

These two reported disease-causing mutations in the gene encoding the $\alpha$-subunit were recessive. Because there are three copies of the $\alpha$-subunit in $F_{1}$, assuming equal assembly between the mutant and wild type forms of the $\alpha$-subunit, just $1 / 8$ th of the $F_{1}$ would be assembled with all wild type $\alpha$-subunit. As discussed earlier, a single mutation that inactivates the catalytic reaction will completely inhibit the enzyme activity [47]. As such, assuming equal probability of assembly of the wild type with the mutant forms, catalytic site mutations will inhibit activity by $7 / 8$ of the total. Apparently, at least for these mutations, incorporation of a mutant copy of the $\alpha$-subunit into the ATP synthase complex did not inactivate the catalytic site. Also, since the mother in the family with the Arg286Cys disease causing mutation expressed just $60 \%$ of the level of the $\alpha$-subunit, a null mutation in the gene encoding the $\alpha$ subunit causing a $50 \%$ decrease is unlikely to be a problem due to haploinsufficiency. Furthermore, there have been no reports to date on dominant mutations in the ATP synthase that are responsible for disease.

\section{Disease-causing mutations in the mitochondrial DNA}

The mitochondrial genome of humans encodes 2 subunits of the mitochondrial ATP synthase - subunits a and 8, with the remaining being encoded in the nucleus (c.f. Table 1). The majority of mutations in the ATP synthase that are associated with disease is located in the mitochondrial ATP6 gene, which encodes subunit-a. This is likely reflective of the importance of subunit-a in the proton translocation.

Disease-causing mutations in the genes encoded in the mitochondrial DNA were first identified in 1990 [144]. The mitochondrial genome is very compact, such that the open reading frames for subunits $-a$ and -8 of the ATP synthase overlap with each other. To date, 29 disease- or phenotype-causing mutations have been reported in the ORF for subunit-a, subunit 6 , and in the region that encodes both subunit-a and -8 (see www.mitomap.org for current listing)

Figure 4a shows a comparison of the primary sequence of subunit-a from E. coli, yeast, and human. Subunit-a is thought to be comprised of 5 transmembrane helices (TMH1-5) and the predicted TMH3-5 are as indicated. Figure $\mathbf{4 b}$ shows the possible arrangement of the transmembrane helices of subunits a ( 5 helices), b ( 2 helices) and c
(20 helices) as determined by cross-linking and other biochemical studies [54, 145-149]. The structure of subunit-a is not known, so this is just a hypothetical representation of the location of the putative helices. a-Arg186 in yeast (210 in E. coli, shaded blue) is conserved and thought to participate directly in the mechanism of proton pumping and thought to be closely associated with Glu59 in subunitc. As such, in the model, the side chain of a-Arg186 is shown close to the carboxylate of c-Glu58. The residues shaded in yellow have been implicated to be associated with the proton half-channel (shown in the model as "On" and "Off" for the direction of proton movement during ATP synthesis) based on chemical modification studies using the enzyme isolated from $E$. coli $[54,150]$. Mutations in 8 residues in the human subunit, including a-Leu156, aLeu217, and a-Leu220, are associated with diseases [144, 151-189]. Residues a-Leu156 and a-Leu217 are highly conserved, adjacent to highly conserved, and located in $\mathrm{TMH} 4$ and TMH5 which contain clusters of residues that have been implicated in proton movement. a-Leu220 is adjacent to TMH5 and abuts highly conserved residues a-Tyr221 and a-Leu222. Based on the clustering of critical residues and the disease forming mutations, it seems likely that TMH4 and $\mathrm{TMH} 5$ are principle players in forming the proton half channels. An attractive hypothesis is that mutations in these residues alter proton movement indirectly by altering the secondary structure, for example a-Leu156Pro, aLeu217Pro, and a-Leu222Pro or directly by impeding proton movement, as with a-Leu156Arg or a-Leu217Arg.

The diseases associated with mutations in the gene encoding subunit-a vary in severity depending upon the allele, but the percentage of the mutant copy in each cell can vary greatly for 2 reasons. Mitochondrial DNA is typically a heteroplasmic mixture of mutant and wild type copies and further, mitochondrial DNA does not segregate in a Mendelian manner. For example, the mutations Leu156Arg, Leu156Pro, Leu217Arg, and Leu217Pro, manifest as NARP (Neurogenic muscle weakness, Ataxia, and Retinitis Pigmentosa) at low heteroplasmy but as Leigh syndrome (severe and fatal encephalopathy) when the percentage of mutant copies of mitochondrial DNA exceeds $90 \%$ (for review, see [190-192]). The disease phenotype is confounded by variations in the percentage of mitochondrial DNA molecules in the cells that contain the mutation, which can vary considerably between tissues and even between cells within a tissue - a situation referred to as "mosaic". The varying genetic background of the patients, the tissue mosaicism, and the resulting variations in heteroplasmy can make interpretation of biochemical data and diagnosis difficult. To circumvent these problems, the effect of the mutation on the function of the ATP synthase has been evaluated by making the corresponding mutation in yeast or $E$. coli followed by biochemical analysis of the resulting mutant enzyme.

Using yeast as a model system, the effect of a deletion mutation in the gene encoding subunit-a on the assembly and function of the ATP synthase was assessed [193]. Subunit-a was shown to be necessary for the activity, but not for the assembly of the ATP synthase, and subcomplexes of 


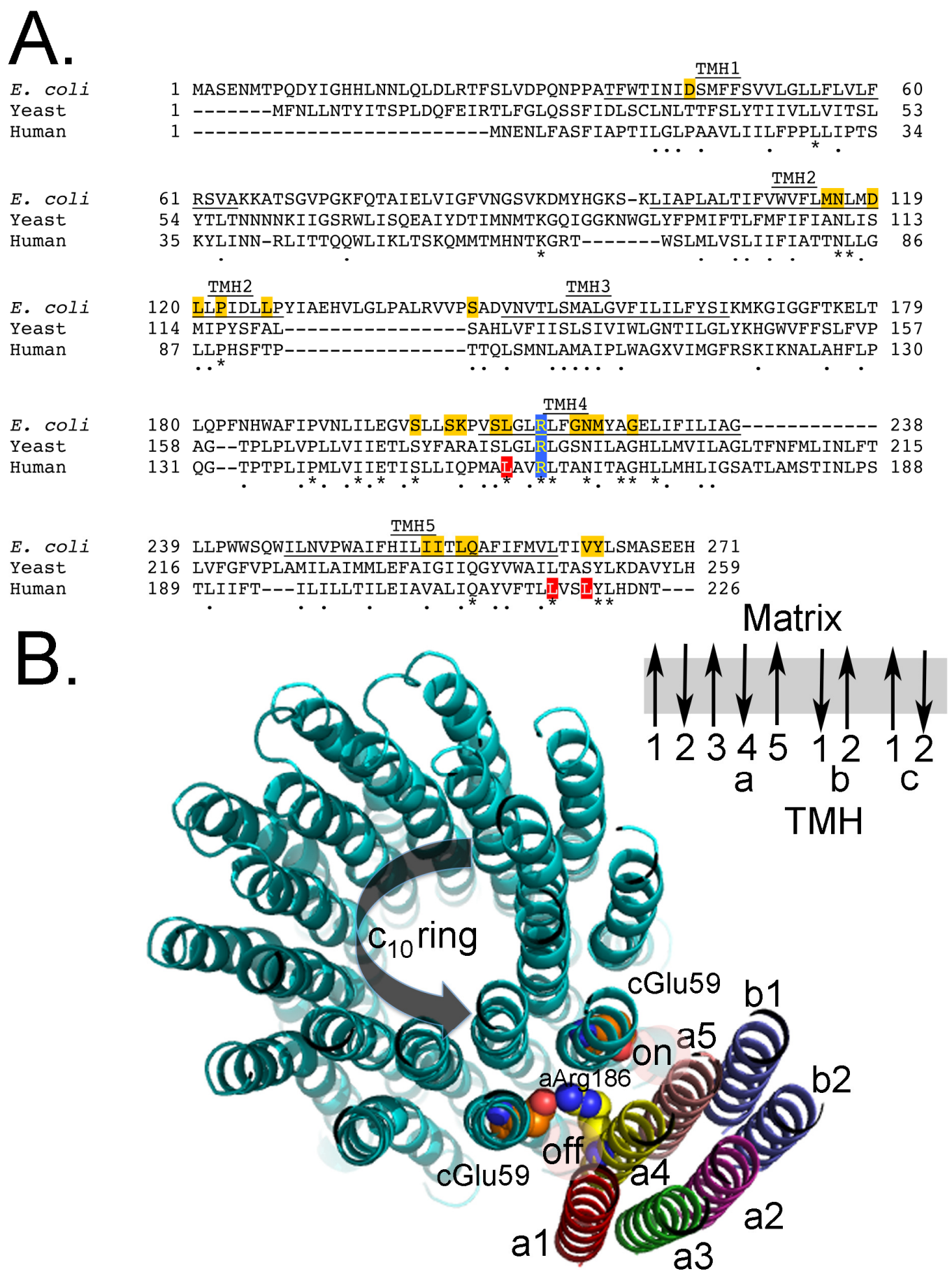

FIGURE 4: Primary sequence alignment of subunit-a. (A) The partial primary sequence alignment of subunit-a from $E$. coli, yeast, and human is shown. The residues predicted to form transmembrane helices 3-5 (TMH3-5) are underlined and labeled [54, 56, 63, 145]. The highly conserved and essential R210 (E. coli numbering) is shaded blue. The residues shaded red are mutated in the discussed human diseases. The residues shaded gold are identified as important for proton movement [54, 204]. (B) Hypothetical model of the arrangement of the helices from subunits $a, b$, and $c$. The helices from subunits a ( 5 helices), b ( 2 helices) and c ( 20 helices) are shown along with the side chains for aArg1876 (yellow/blue) and c-Glu59 (red). There is very little cross-linking data positioning Helix 1 of subunit-a and thus the position is inferred from the absence, rather than presence, of cross-linking. Subunit b is thought to have a stoichiometry of 2 in the $E$. coli enzyme and 1 in the mitochondrial enzyme and there is 1 transmembrane helix in the bacterial subunit and 2 in the mitochondrial subunit. This view is from the matrix side of the mitochondrion. Also shown is the relative direction for deportation/protonation of c-Glu59 during ATP synthesis. The black arrow indicates the direction of rotation during ATP synthesis. Also shown is a schematic of the orientation of the transmembrane helices (TMH) for subunits $a, b$, and $c$ in the membrane. Note that the helices for the subunits-a and - $b$ are representations of a possible placement and secondary structure, while the structure of the c-ring is a crystal structure obtained from yeast [8]. 
the enzyme can be formed devoid of subunit-a. The ATPase activity was at near normal levels but it was nearly insensitive to the $F_{0}$ inhibitor, oligomycin. The cells rapidly lost mitochondrial DNA when the selection for the mitochondrial DNA was relaxed. The cells lost cytochrome oxidase activity, as was noted for deletion mutations in genes encoding other subunits of the ATP synthase discussed earlier. However, this study demonstrated that the loss of cytochrome oxidase activity was due to the loss in the synthesis of mitochondrial encoded subunit 1 of cytochrome oxidase, Cox1p. This causal relationship was further supported by studies in yeast and human fibroblast cells that showed that cytochrome oxidase activity was decreased in cells treated with oligomycin and partial recovery was caused by addition of an uncoupler [194]. In yeast, oligomycin caused a loss of Cox1p synthesis similar to that observed with the prior study with subunit-a deficient cells. These studies suggest that hyperpolarization of the mitochondrial membrane may compromise the synthesis of subunit 1 of cytochrome oxidase as addition of a limiting amount of uncoupler can restore cytochrome oxidase. Hyperpolarization of the mitochondrial membrane can be the result of mutation that inactivate or inhibit activity of the ATP synthase, thus establishing a possible link with cytochrome oxidase. Thus, as discussed earlier, there appears to be an evolutionary conserved link between a functional ATP synthase and synthesis of cytochrome oxidase and possibly the $\Delta \Psi$ of the mitochondrial membrane is that link.

The biochemical consequences of a-Leu156Arg mutation were studied by making the corresponding mutation in $E$. coli [195]. The mutant enzyme had enzymatic properties that were nearly identical to the enzyme devoid of subunit-a. As such, in E. coli, mutations that affect the folding of subunit-a and assembly of the holo-enzyme cannot be firmly distinguished from mutations in subunit-a that do not prevent assembly, but rather impair the activity of the enzyme, simply by measuring the levels of ATP hydrolysis and synthesis. The analysis of the cultured fibroblasts [177] and cybrids [196] containing the Leu156Arg mutation indicated that the $\mathrm{P} / \mathrm{O}$ ratio of the affected mitochondria [177] was not altered, but there was a decrease in both the level of ATP synthase and respiratory activity, and the mutation seemed to destabilize the complex [196]. Interestingly, the Leu156Arg mutation made the ATPase activity hypersensitive to oligomycin $[177,196]$. One explanation for this effect that is consistent with the mode of oligomycin binding to subunit c [52] is that the mutation in subunit-a made the binding site more accessible to oligomycin.

Similarly, subunit-a mutations, Leu217Arg, Leu217Pro, Leu156Arg, and Leu156Pro, were also studied using $E$. coli enzyme [161]. The mutation Leu217Arg did not largely alter the level of the ATP synthase, but severely inhibited ATP hydrolysis and ATP synthesis by the membrane bound enzyme. These results may indicate that the mutation blocks the proton conduction pathway in the ATP synthase without uncoupling the enzyme. In contrast, the Leu217Pro mutant form had considerable ATP synthase activity thus clearly showing biochemical differences due to the allelic differences. The mutations Leu156Arg and Leu156Pro caused diminished ATPase and ATP synthase activity but had little effect on the coupling of the enzyme. When the corresponding mutations, Leu156Pro and Leu156Arg, were made in yeast $S$. cerevisiae and analyzed, they demonstrated a decrease in the level of ATPase and ATP synthase activity, and again, a pleiotropic effect on the level of cytochrome oxidase activity $[197,198]$. For the yeast enzyme with Leu156Arg, the enzyme appeared to be fully assembled but defective in proton pumping and ATP synthesis. For the yeast enzyme with Leu156Pro, the decreased level of ATP synthase activity paralleled the decrease in oligomycin sensitivity suggesting that subunit-a was not efficiently incorporated into the ATP synthase. The effect of these mutations on the biochemistry of the bacterial and yeast enzymes were entirely consistent with the proposed role of subunit-a as providing a half-channel for proton access to the essential carboxylate in subunit-c, access to the intermembrane space, and the matrix space of the mitochondrion.

Disease-causing mutations in subunit 8 are much less common than those in subunit-a. The mutation $\operatorname{Trp} 55 \mathrm{X}$, where $X$ is a stop codon, results in the truncation of 14 amino acids from the C-terminus of subunit 8 [199]. The resulting effect is a destabilization of the ATP synthase complex such that there was a large decrease in the level of intact ATP synthase complex and an increase in the amount of free $F_{1}$ ATPase, as judged by Blue Native gels. It would be rather remarkable if the Blue Native gels accurately reflected the level of free $F_{1}$ ATPase in the cells as a high level of free $F_{1}$ would lead to a high level of futile and wasteful ATP hydrolysis. Possibly the ATP synthase complex is intact in the cell and only falls apart during the gel analysis. Alternatively, it is possible that the natural inhibitor protein, Inh1, is able to prevent the hydrolysis of ATP by free $F_{1}$ ATPase. No other biochemical studies were done to give any insight into the effect of this mutation on the function of the ATP synthase.

There was a mutation in the overlapping region of the open reading frames of subunit-a and subunit-8 [200]. The mutation created a Thr55Arg replacement in subunit- 8 and a Met1Thr replacement in subunit-a. The fibroblasts from the patient showed a significant, but not dramatic decrease in the ATP synthase activity driven by malate/glutamate or succinate. Likely, the change in the initiating codon for subunit-a resulted in a decrease in the level of subunit-a and thus in a decrease in the intact ATP synthase complex.

Single nucleotide polymorphisms (SNPs) in the nuclear genes encoding subunits of the ATP synthase

With the advent of rapid sequence analysis of the human genome, the bottleneck for the understanding of individual genetic differences is now the analysis of the effect of single nucleotide polymorphisms on biochemistry of the enzyme and the resulting effect on the physiology of the cell and organism. This analysis will be greatly aided by the understanding of the structure/function relationship of the protein and by the library of mutations that have already been studied. Nonetheless, the analysis is difficult and 
generally unpredictable - as was the case for the diseasecausing mutation identified in the gene encoding the $\alpha$ subunit and discussed earlier [142]. The difficulty can be illustrated by looking at the current library of the SNPs in the gene encoding the human $\gamma$-subunit of the ATP synthase (ATP5C1).

Many SNPs have been mapped in ATP5C1 (see http://evs.gs.washington.edu/EVS/). Note, mutations in genetic databases are normally numbered using the initiating Met as 1, while the convention used here and in structural and biochemical studies is that the first amino acid in the mature peptide is numbered 1 . In the case of the human $\gamma$-subunit, there is a 25 amino acid leader polypeptide that targets the subunit to the mitochondria. Current SNPs that create missense mutations in the mature $\gamma$-subunit are: Ile6Val, Met25Thr, Ala32Val, Pro40Ser, Ala50Val, lle85Val, Ile144Val, Ile169The, Ser186Asn, Tyr214Cys, Arg252Cys, Gly268Ser (Figure 5). $\gamma$-Met25 interacts with $\beta$ Ile 390, which is in the Catch 2 region. The mutation in $E$. coli $\mathrm{Y}$-subunit that corresponds to Met25Lys partially uncoupled the enzyme, reduced the binding affinity for $\mathrm{Pi}$ and reduced the apparent affinity for ATP of the $E$. coli enzyme [201-203]. However, it is not known if Met25Thr affects the biochemistry of the human enzyme.

The SNPs are not limited to the $\gamma$-subunit, but occur in some of the other genes encoding other subunits of the
ATP synthase including the $\alpha$ - and $\beta$ - subunits. Notwithstanding the putative importance of any one residue in the ATP synthase, the effect of a residue-altering mutation on the biochemistry of the enzyme is uncertain. Furthermore, the relationship between function of the ATP synthase and physiology of the organism is unclear. How much change in the coupling or activity of the ATP synthase is needed to have an observable effect on the individual? Do these SNPS account for differences in the individual's performances in different climates, physical activities, or recovery from a trauma, such as a heart attack? The future lies in the ability to link SNPs with physical and medical risks or advantages for any one individual. Can we use yeast as a model organism to assess the effect of SNPs on the structure and activity of the enzyme?

A major impediment to the understanding of the ATP synthase is the lack of a high-resolution structure of the entire enzyme complex. The most pertinent portion of the enzyme that is lacking structural details is the proton halfchannels, and this severely limits our understanding of the mechanism of proton translocation and pumping. The recent advances in electron microscopy make it inevitable that the structure of the ATP synthase will be solved but there is still hope that a high-resolution crystal structure will be obtained. However, structure determination of the mutant forms of the enzyme will likely also be necessary to

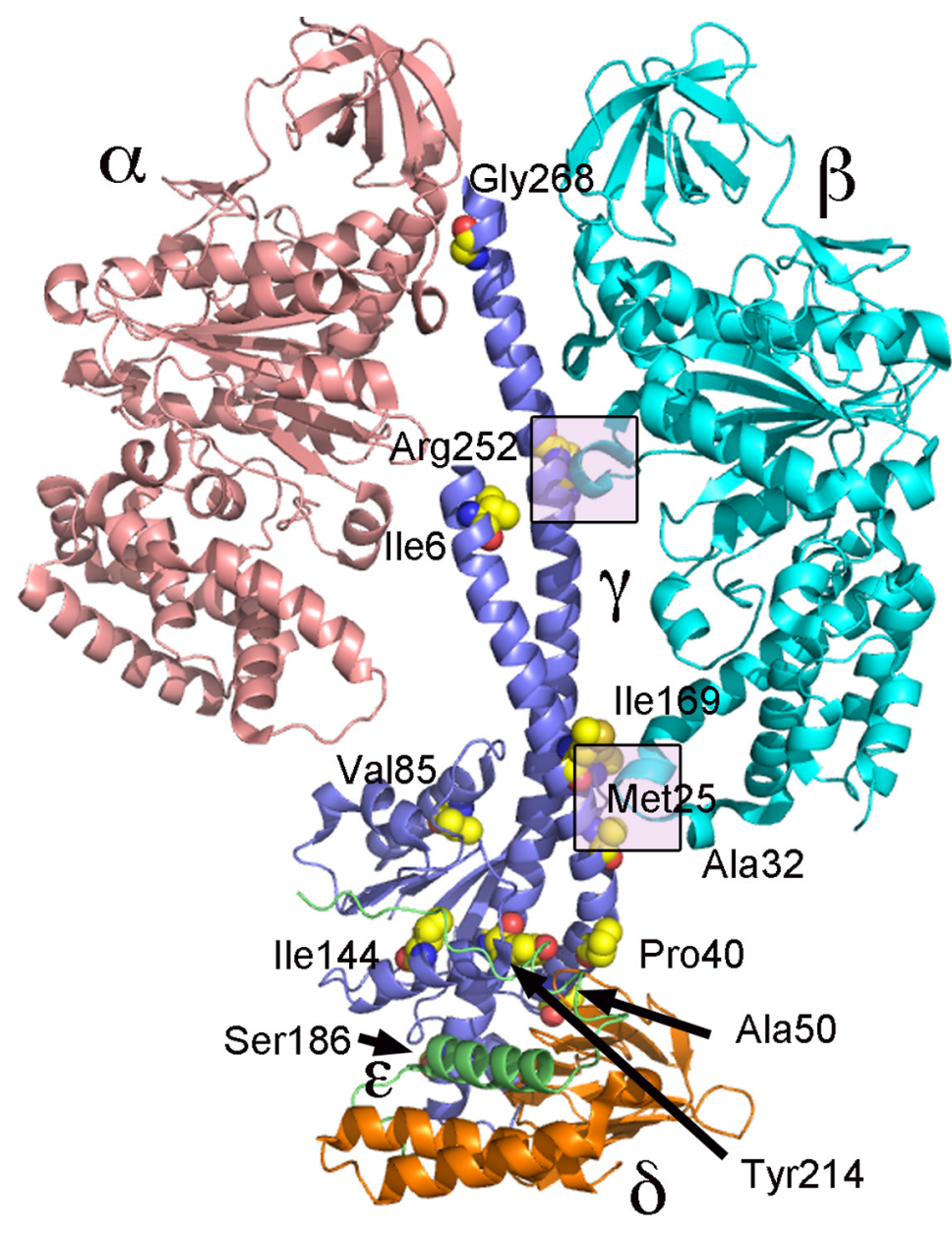

FIGURE 5: Relative location in the ATP synthase of residues mutated by known single nucleotide polymorphisms. The structural representation is derived from the $x$-ray crystal structure of the bovine ATPase (1E79). To simplify the image, only a single copy of the $\alpha$ - (salmon) and $\beta$ - (cyan) subunits is shown along with the $\gamma$ - (purple), $\delta$ - (orange), and $\varepsilon$ - (green) subunits. The residues, which are altered by known SNPs in the $\gamma$-subunit are shown in sphere representation and numbered using the human numbering system with 1 as the first residue in the mature peptide (the initiating Met is - 25 for the $\gamma$-subunit). The two boxes represent the regions corresponding to Catch 1 and Catch 2 regions. 
fully understand the effect of disease causing mutations, especially in subunit a, and the effect of SNPs on the structure and function of the enzyme.

\section{ACKNOWLEDGMENTS}

The work was supported by a grant from NIH: R01GM66223. Thanks to Drs. John Walker and Andrew Leslie for their past support and discussions, Drs. Alexander Tzagoloff and Rosemary Stuart for their discussions and thoughtful insights, Dr. Vamsi Mootha for his collaborative interactions and editing the manuscript, Dr. Jindrich Symersky his past and current collaborative interactions.

\section{CONFLICT OF INTEREST}

The authors declare no conflict of interest.

\section{COPYRIGHT}

(C) $2015 \mathrm{Xu}$ et al. This is an open-access article released under the terms of the Creative Commons Attribution (CC BY) license, which allows the unrestricted use, distribution, and reproduction in any medium, provided the original author and source are acknowledged.

Please cite this article as: Ting Xu, Vijayakanth Pagadala, David M. Mueller (2015). Understanding structure, function, and mutations in the mitochondrial ATP synthase. Microbial Cell 2(4): 105-125. doi: 10.15698/mic2015.04.197

\section{REFERENCES}

1. Mitchell P. (1961) Coupling of phosphorylation to electron and hydrogen transfer by a chemi-osmotic type mechanism. Nature 191, 144-148.

2. Boyer PD, Cross RL, and Momsen W. (1973) A new concept for energy coupling in oxidative phosphorylation based on a molecular explanation of the oxygen exchange reactions. Proc Natl Acad Sci USA 70, 2837-2839.

3. Watt IN, Montgomery MG, Runswick MJ, Leslie AG, and Walker JE. (2010) Bioenergetic cost of making an adenosine triphosphate molecule in animal mitochondria. Proc Natl Acad Sci USA 107, 1682316827.

4. Lee CP, Gu Q, Xiong Y, Mitchell RA, and Ernster L. (1996) P/O ratios reassessed: mitochondrial $\mathrm{P} / \mathrm{O}$ ratios consistently exceed 1.5 with succinate and 2.5 with NAD-linked substrates. FASEB J 10, 345-350.

5. Hinkle PC. (2005) P/O ratios of mitochondrial oxidative phosphorylation. Biochim Biophys Acta 1706, 1-11.

6. Kerscher SJ. (2000) Diversity and origin of alternative NADH:ubiquinone oxidoreductases. Biochim Biophys Acta 1459, 274283.

7. Kabaleeswaran V, Puri N, Walker JE, Leslie AG, and Mueller DM. (2006) Novel features of the rotary catalytic mechanism revealed in the structure of yeast $F_{1}$ ATPase. EMBO J 25,5433-5442.

8. Symersky J, Pagadala V, Osowski D, Krah A, Meier T, FaraldoGomez JD, and Mueller DM. (2012) Structure of the $c_{10}$ ring of the yeast mitochondrial ATP synthase in the open conformation. Nat Struct Mol Biol 19, 485-491.

9. Rees DM, Leslie AG, and Walker JE. (2009) The structure of the membrane extrinsic region of bovine ATP synthase. Proc Natl Acad Sci USA 106, 21597-21601.

10. Kane Dickson V, Silvester JA, Fearnley IM, Leslie AGW, and Walker JE. (2006) On the structure of the stator of the mitochondrial ATP synthase. EMBO J 25, 2911-2918.

11. Walker JE, and Dickson VK. (2006) The peripheral stalk of the mitochondrial ATP synthase. Biochim Biophys Acta 1757, 286-296.

12. Abrahams JP, Leslie AGW, Lutter R, and Walker JE. (1994) Structure at $2.8 \AA$ resolution of $F_{1}$-ATPase from bovine heart mitochondria. Nature 370, 621-628.

13. Rees DM, Montgomery MG, Leslie AG, and Walker JE. (2012) Structural evidence of a new catalytic intermediate in the pathway of
ATP hydrolysis by $F_{1}$-ATPase from bovine heart mitochondria. Proc Natl Acad Sci USA 109, 11139-11143.

14. Abrahams JP, Buchanan SK, Van Raaij MJ, Fearnley IM, Leslie AGW, and Walker JE. (1996) The structure of bovine $F_{1}$-ATPase complexed with the peptide antibiotic efrapeptin. Proc Natl Acad Sci USA 93, 9420-9424.

15. Van Raaij MJ, Abrahams JP, Leslie AGW, and Walker JE. (1996) The structure of bovine $F_{1}$-ATPase complexed with the antibiotic inhibitor aurovertin B. Proc Natl Acad Sci USA 93, 6913-6917.

16. Braig K, Menz RI, Montgomery MG, Leslie AGW, and Walker JE. (2000) Structure of bovine mitochondrial $\mathrm{F}_{1}$-ATPase inhibited by $\mathrm{Mg}^{2+}$ ADP and aluminium fluoride. Structure Fold Des 8, 567-573.

17. Gibbons C, Montgomery MG, Leslie AGW, and Walker JE. (2000) The structure of the central stalk in bovine $F_{1}$-ATPase at $2.4 \AA$ resolution. Nat Struct Biol 7, 1055-1061.

18. Menz RI, Walker JE, and Leslie AGW. (2001) Structure of bovine mitochondrial $F_{1}$-ATPase with nucleotide bound to all three catalytic sites. implications for the mechanism of rotary catalysis. Cell 106, 331341.

19. Kagawa R, Montgomery MG, Braig K, Leslie AGW, and Walker JE. (2004) The structure of bovine $F_{1}$-ATPase inhibited by ADP and beryllium fluoride. EMBO J 23, 2734-2744.

20. Bowler MW, Montgomery MG, Leslie AGW, and Walker JE. (2006) How azide inhibits ATP hydrolysis by the F-ATPases. Proc Natl Acad Sci USA 103, 8646-8649.

21. Bowler MW, Montgomery MG, Leslie AG, and Walker JE. (2007) Ground state structure of $F_{1}$-ATPase from bovine heart mitochondria at 1.9Å resolution. J Biol Chem 282, 14238-14242.

22. Gledhill JR, Montgomery MG, Leslie AG, and Walker JE. (2007) Mechanism of inhibition of bovine $F_{1}$-ATPase by resveratrol and related polyphenols. Proc Natl Acad Sci USA 104, 13632-13637.

23. Bianchet MA, Hullihen J, Pedersen PL, and Amzel LM. (1998) The 2.8-Å structure of rat liver $F_{1}$-ATPase: Configuration of a critical intermediate in ATP synthesis/hydrolysis. Proc Natl Acad Sci USA 95, $11065-11070$

24. Nakamoto RK, Shin K, Iwamoto A, Omote $H$, Maeda $M$, and Futai M. (1992) Escherichia coli $\mathrm{F}_{0} \mathrm{~F}_{1}$-ATPase. Residues involved in catalysis and coupling. Ann NY Acad Sci. 671, 335-344. 
25. Shen H, Yao B-Y, and Mueller DM. (1994) Primary structural constraints of P-loop of mitochondrial $F_{1}$-ATPase from yeast. J Biol Chem 269, 9424-9428.

26. Dittrich M, Hayashi S, and Schulten K. (2003) On the mechanism of ATP hydrolysis in $\mathrm{F}_{1}$-ATPase. Biophys J 85, 2253-2266.

27. Komoriya $Y$, Ariga T, lino R, and Noji H. (2012) Principal role of the arginine finger in rotary catalysis of F1-ATPase. J Biol Chem 287, 15134-15142

28. Noji H, Yasuda R, Yoshida M, and Kinosita K, Jr. (1997) Direct observation of the rotation of $F_{1}$-ATPase. Nature 386, 299-302.

29. Itoh H, Takahashi A, Adachi K, Noji H, Yasuda R, Yoshida M, and Kinosita K. (2004) Mechanically driven ATP synthesis by $F_{1}$-ATPase. Nature 427, 465-468.

30. Rondelez Y, Tresset G, Nakashima T, Kato-Yamada Y, Fujita $H$ Takeuchi S, and Noji H. (2005) Highly coupled ATP synthesis by F1ATPase single molecules. Nature 433, 773-777.

31. Yasuda R, Noji H, Yoshida M, Kinosita K, Jr., and Itoh H. (2001) Resolution of distinct rotational substeps by submillisecond kinetic analysis of $F_{1}$-ATPase. Nature 410, 898-904.

32. Yasuda R, Noji H, Kinosita K, Jr., and Yoshida M. (1998) $F_{1}$-ATPase is a highly efficient molecular motor that rotates with discrete 120 steps. Cell 93, 1117-1124.

33. Nishizaka T, Oiwa K, Noji H, Kimura S, Muneyuki E, Yoshida M, and Kinosita K, Jr. (2004) Chemomechanical coupling in $F_{1}$-ATPase revealed by simultaneous observation of nucleotide kinetics and rotation. Nat Struct Mol Biol 11, 142-148.

34. Adachi K, Oiwa K, Nishizaka T, Furuike S, Noji H, Itoh H, Yoshida M, and Kinosita K, Jr. (2007) Coupling of rotation and catalysis in $F_{1-}$ ATPase revealed by single-molecule imaging and manipulation. Cell 130, 309-321.

35. Steel BC, Nord AL, Wang Y, Pagadala V, Mueller DM, and Berry RM. (2015) Comparison between single-molecule and $X$-ray crystallography data on yeast $F_{1}$-ATPase. Scientific Reports 5, 8773.

36. Nakanishi-Matsui M, Kashiwagi S, Hosokawa H, Cipriano DJ, Dunn SD, Wada Y, and Futai M. (2006) Stochastic high-speed rotation of Escherichia coli ATP synthase $F_{1}$ sector: the e subunit-sensitive rotation. J Biol Chem 281, 4126-4131.

37.Omote H, Sambonmatsu N, Saito K, Sambongi Y, Iwamoto-Kihara A Yanagida T, Wada Y, and Futai M. (1999) The g-subunit rotation and torque generation in $\mathrm{F}_{1}$-ATPase from wild-type or uncoupled mutant Escherichia coli. Proc Natl Acad Sci USA 96, 7780-7784.

38. Bilyard T, Nakanishi-Matsui M, Steel BC, Pilizota T, Nord AL, Hosokawa H, Futai M, and Berry RM. (2013) High-resolution singlemolecule characterization of the enzymatic states in Escherichia coli F1-ATPase. Philos Trans R Soc Lond B Biol Sci 368, 20120023.

39. Spetzler D, York J, Daniel D, Fromme R, Lowry D, and Frasch W. (2006) Microsecond time scale rotation measurements of single $F_{1^{-}}$ ATPase molecules. Biochemistry 45, 3117-3124.

40. Martin JL, Ishmukhametov R, Hornung $T$, Ahmad Z, and Frasch WD. (2014) Anatomy of $F_{1}$-ATPase powered rotation. Proc Natl Acad Sci USA $111,3715-3720$.

41. Suzuki T, Tanaka K, Wakabayashi C, Saita E, and Yoshida M. (2014) Chemomechanical coupling of human mitochondrial $F_{1}$-ATPase motor. Nat Chem Biol 10, 930-936.

42. Choate GL, Hutton RL, and Boyer PD. (1979) Occurance and significance of oxygen exchange reactions catalyzed by mitochondrial adenosine triphosphatase preparations. J Biol Chem 254, 286-290.
43. Grubmeyer C, Cross RL, and Penefsky HS. (1982) Mechanism of ATP hydrolysis by beef heart mitochondrial ATPase. Rate constants for elementary steps in catlysis at a single site. J Biol Chem 257, 12092 12100.

44. Cross RL, Grubmeyer C, and Penefsky HS. (1982) Mechanism of ATP hydrolysis by beef heart mitochondrial ATPase. Rate enhancements resulting from cooperative interactions between multiple catalytic sites. J Biol Chem 258, 12101-12105.

45. Mueller DM, Indyk V, and McGill L. (1994) ATPase kinetics for wildtype Saccharomyces cerevisiae $\mathrm{F}_{1}$-ATPase and $\mathrm{F}_{1}$-ATPase with the $\mathrm{b}$ subunit Thr197-->Ser mutation. Eur J Biochem 222, 991-999.

46. Kinosita K, Jr., Adachi K, and Itoh H. (2004) Rotation of $F_{1}$-ATPase: how an ATP-driven molecular machine may work. Annu Rev Biophys Biomol Struct 33, 245-268.

47. Amano T, Hisabori T, Muneyuki E, and Yoshida M. (1996) Catalytic activities of $a_{3} b_{3}$ gamma complexes of $F_{1}$ - ATPase with 1,2 , or 3 incompetent catalytic sites. J Biol Chem 271, 18128-18133.

48. Ariga T, Masaike T, Noji H, and Yoshida M. (2002) Stepping rotation of $F_{1}$-ATPase with one, two, or three altered catalytic sites that bind ATP only slowly. J Biol Chem 277, 24870-24874.

49. Kagawa Y, and Racker E. (1966) Partial resolution of the enzymes catalyzing oxidative phosphorylation. 8. Properties of a factor conferring oligomycin sensitivity on mitochondrial adenosine triphosphatase. J Biol Chem 241, 2461-2466.

50. Racker E. (1964) A reconstituted system of oxidative phosphorylation. Biochem Biophys Res Commun 14, 75-78.

51. Racker E. (1963) A mitochondrial factor conferring oligomycin sensitivity on soluble mitochondrial ATPase. Biochem Biophys Res Commun 10, 435-439.

52. Symersky J, Osowski D, Walters DE, and Mueller DM. (2012) Oligomycin frames a common drug-binding site in the ATP synthase. Proc Natl Acad Sci USA 109, 13961-13965.

53. Collinson IR, Runswick MJ, Buchanan SK, Fearnley IM, Skehel JM, Van Raaij MJ, Griffiths DE, and Walker JE. (1994) $F_{0}$ membrane domain of ATP synthase from bovine heart mitochondria: purification, subunit composition, and reconstitution with $\mathrm{F}_{1}$-ATPase. Biochemistry 33, 7971-7978.

54. Dong $\mathrm{H}$, and Fillingame RH. (2010) Chemical reactivities of cysteine substitutions in subunit a of ATP synthase define residues gating $\mathrm{H}^{+}$ transport from each side of the membrane. J Biol Chem 285, 3981139818.

55. Fillingame RH, Angevine CM, and Dmitriev OY. (2003) Mechanics of coupling proton movements to c-ring rotation in ATP synthase. FEBS Lett 555, 29-34.

56. Long JC, Wang S, and Vik SB. (1998) Membrane topology of subunit a of the $F_{1} F_{0}$ ATP synthase as determined by labeling of unique cysteine residues. J Biol Chem 273, 16235-16240.

57. Baker LA, Watt IN, Runswick MJ, Walker JE, and Rubinstein JL. (2012) Arrangement of subunits in intact mammalian mitochondrial ATP synthase determined by cryo-EM. Proc Natl Acad Sci USA 109, 11675-11680.

58. Stock D, Leslie AGW, and Walker JE. (1999) Molecular architecture of the rotary motor in ATP synthase. Science 286, 1700-1705.

59. Meier T, Polzer P, Diederichs K, Welte W, and Dimroth P. (2005) Structure of the rotor ring of F-Type $\mathrm{Na}^{+}$-ATPase from llyobacter tartaricus. Science 308, 659-662. 
60. Matthies D, Preiss L, Klyszejko AL, Muller DJ, Cook GM, Vonck J, and Meier T. (2009) The $\mathrm{c}_{13}$ ring from a thermoalkaliphilic ATP synthase reveals an extended diameter due to a special structural region. J Mol Biol 388, 611-618.

61. Vollmar M, Schlieper D, Winn M, Buchner C, and Groth G. (2009) Structure of the $\mathrm{C}_{14}$ rotor ring of the proton translocating chloroplast ATP synthase. J Biol Chem 284, 18228-18235.

62. Pogoryelov D, Yildiz Ö, Faraldo-Gómez JD, and Meier T. (2009) High-resolution structure of the rotor ring of a proton-dependent ATP synthase. Nat Struct Mol Biol 16, 1068-1073.

63. Vik SB, Long JC, Wada T, and Zhang D. (2000) A model for the structure of subunit a of the Escherichia coli ATP synthase and its role in proton translocation. Biochim Biophys Acta 1458, 457-466.

64. Lau WC, and Rubinstein JL. (2010) Structure of intact Thermus thermophilus V-ATPase by cryo-EM reveals organization of the membrane-bound $V_{0}$ motor. Proc Natl Acad Sci USA 107, 1367-1372.

65. Velours J, Vailler J, Paumard P, Soubannier V, Lai-Zhang J, and Mueller DM. (2001) Bovine coupling fator 6 , with just $14.5 \%$ shared identity, replaces subunit $h$ in the yeast Saccharomyces cerevisiae ATP synthase. J Biol Chem 276, 8602-8607.

66. Walker JE, Lutter R, Dupuis A, and Runswick MJ. (1991) Identification of the subunits of $F_{1} F_{0}$-ATPase from bovine heart mitochondria. Biochemistry 30, 5369-5378.

67. Spannagel C, Vaillier J, Arselin G, Graves PV, and Velours J. (1997) The subunit $f$ of mitochondrial yeast ATP synthase - Characterization of the protein and disruption of the structural gene ATP17. Eur J Biochem 247, 1111-1117.

68. Vaillier J, Arselin G, Graves PV, Camougrand N, and Velours J. (1999) Isolation of supernumerary yeast ATP synthase subunits e and i. Characterization of subunit $i$ and disruption of its structural gene ATP18. J Biol Chem 274, 543-548.

69. Arnold I, Pfeiffer K, Neupert W, Stuart RA, and Schägger H. (1999) ATP synthase of yeast mitochondria - Isolation of subunit $j$ and disruption of the ATP18 gene. J Biol Chem 274, 36-40.

70. Lai-Zhang J, Xiao Y, and Mueller DM. (1999) Epistatic interactions of deletion mutants in the genes encoding the $F_{1}$ - ATPase in yeast Saccharomyces cerevisiae. EMBO J 18, 58-64.

71. Arnold I, Pfeiffer K, Neupert W, Stuart RA, and Schägger H. (1998) Yeast mitochondrial $F_{1} F_{0}-A T P$ synthase exists as a dimer: identification of three dimer-specific subunits. EMBO J. 17, 7170-7178.

72. Davies KM, Strauss M, Daum B, Kief JH, Osiewacz HD, Rycovska A, Zickermann V, and Kuhlbrandt W. (2011) Macromolecular organization of ATP synthase and complex I in whole mitochondria. Proc Natl Acad Sci USA 108, 14121-14126.

73. Seelert $H$, and Dencher NA. (2011) ATP synthase superassemblies in animals and plants: two or more are better. Biochim Biophys Acta 1807, 1185-1197.

74. Paumard P, Vaillier J, Coulary B, Schaeffer J, Soubannier V, Mueller DM, Brethes D, di Rago JP, and Velours J. (2002) The ATP synthase is involved in generating mitochondrial cristae morphology. EMBO J 21, 221-230.

75. Arselin G, Vaillier J, Salin B, Schaeffer J, Giraud MF, Dautant A, Brethes D, and Velours J. (2004) The modulation in subunits e and $g$ amounts of yeast ATP synthase modifies mitochondrial cristae morphology. J Biol Chem 279, 40392-40399.

76. Boyle GM, Roucou X, Nagley P, Devenish RJ, and Prescott M. (1999) Identification of subunit $g$ of yeast mitochondrial $F_{1} F_{0^{-}}$ATP synthase, a protein required for maximal activity of cytochrome $c$ oxidase. Eur.J.Biochem. 262, 315-323.
77. Saddar S, Dienhart $M K$, and Stuart RA. (2008) The $F_{1} F_{0}$-ATP synthase complex influences the assembly state of the cytochrome bc $_{1}$-cytochrome oxidase supercomplex and its association with the TIM23 machinery. J Biol Chem 283, 6677-6686.

78. Shen H, Walters DE, and Mueller DM. (2008) Introduction of the chloroplast redox regulatory region in the yeast ATP synthase impairs cytochrome c oxidase. J Biol Chem 283, 32937-32943.

79. Pullman ME, and Monroy GC. (1963) A naturally occurring inhibitor of mitochondrial adenosine triphosphatase. J Biol Chem 238, 37623769 .

80.Akashi A, Yoshida Y, Nakagoshi H, Kuroki K, Hashimoto T, Tagawa K, and Imamoto F. (1988) Molecular cloning and expression of a gene for a factor which stabilizes formation of inhibitor-mitochondrial ATPase complex from Saccharomyces cerevisiae. J Biochem 104, 526-530.

81. Ichikawa N, Yoshida Y, Hashimoto T, Ogasawara N, Yoshikawa H, Imamoto F, and Tagawa K. (1990) Activation of ATP hydrolysis by an uncoupler in mutant mitochondria lacking an intrinsic ATPase inhibitor in yeast. J Biol Chem. 265, 6274-6278.

82. Rouslin W, and Broge CW. (1993) Mechanisms of ATP conservation during ischemia in slow and fast heart rate hearts. Am J Physiol 264, c209-216.

83. Rouslin W. (1991) Regulation of the mitochondrial ATPase in situ in cardiac muscle: role of the inhibitor subunit. J Bioenerg Biomembr 23, 873-888.

84. Rouslin W, and Broge CW. (1989) Regulation of mitochondrial matrix $\mathrm{pH}$ and adenosine 5 '-triphosphatase activity during ischemia in slow heart-rate hearts. Role of $\mathrm{Pi} / \mathrm{H}^{+}$symport. J Biol Chem 264, 1522415229.

85. Rouslin W. (1987) Factors affecting the reactivation of the oligomycin-sensitive adenosine 5'-triphosphatase and the release of ATPase inhibitor protein during the re-energization of intact mitochondria from ischemic cardiac muscle. J Biol Chem 262, 34723476.

86. Rouslin W, and Erickson JL. (1986) Factors affecting the loss of mitochondrial function in autolyzing cardiac muscle. J Mol Cell Cardiol 18, 1187-1195.

87. Campanella M, Casswell E, Chong S, Farah Z, Wieckowski MR, Abramov AY, Tinker A, and Duchen MR. (2008) Regulation of mitochondrial structure and function by the $F_{1} F_{0}$-ATPase inhibitor protein, IF1. Cell Metab 8, 13-25.

88. Rak M, Gokova S, and Tzagoloff A. (2011) Modular assembly of yeast mitochondrial ATP synthase. EMBO J 30, 920-930.

89. Lopez-Martinez G, Rodriguez-Porrata B, Margalef-Catala M, and Cordero-Otero R. (2012) The STF2p hydrophilin from Saccharomyces cerevisiae is required for dehydration stress tolerance. PLoS One 7, e33324.

90. Fujikawa M, Imamura H, Nakamura J, and Yoshida M. (2012) Assessing actual contribution of IF1, inhibitor of mitochondrial $F_{0} F_{1}$, to ATP homeostasis, cell growth, mitochondrial morphology, and cell viability. J Biol Chem 287, 18781-18787.

91. Cabezón E, Montgomery MG, Leslie AGW, and Walker JE. (2003) The structure of bovine $F_{1}$-ATPase in complex with its regulatory protein IF1. Nat Struct Biol 10, 744-750.

92. Bason JV, Montgomery MG, Leslie AG, and Walker JE. (2014) Pathway of binding of the intrinsically disordered mitochondrial inhibitor protein to $F_{1}$-ATPase. Proc Natl Acad Sci USA 111, 1130511310. 
93. Tsunoda SP, Rodgers AJ, Aggeler R, Wilce MC, Yoshida M, and Capaldi RA. (2001) Large conformational changes of the epsilon subunit in the bacterial $F_{1} F_{0}$ ATP synthase provide a ratchet action to regulate this rotary motor enzyme. Proc Natl Acad Sci USA 98, 65606564.

94. Rizzo JM, Tarsio M, Martinez-Munoz GA, and Kane PM. (2007) Diploids heterozygous for a vma13D mutation in Saccharomyces cerevisiae highlight the importance of V-ATPase subunit balance in supporting vacuolar acidification and silencing cytosolic $\mathrm{V}_{1}$-ATPase activity. J Biol Chem 282, 8521-8532.

95. Li SC, Diakov TT, Rizzo JM, and Kane PM. (2012) Vacuolar $\mathrm{H}^{+}$ATPase works in parallel with the HOG pathway to adapt Saccharomyces cerevisiae cells to osmotic stress. Eukaryot Cell 11 , 282-291.

96. Ackerman SH. (2002) Atp11p and Atp12p are chaperones for $F_{1-}$ ATPase biogenesis in mitochondria. Biochim Biophys Acta 1555, 101 105.

97. Wang ZG, White PS, and Ackerman SH. (2001) Atp11p and Atp12p are assembly factors for the $\mathrm{F}_{1}$-ATPase in human mitochondria. J Biol Chem 276, 30773-30778.

98. Wang ZG, and Ackerman SH. (2000) The assembly factor Atp11p binds to the b-subunit of the mitochondrial $F_{1}$-ATPase. J Biol Chem $275,5767-5772$

99. Wang ZG, and Ackerman SH. (1996) Identification of functional domains in Atp11p - Protein required for assembly of the mitochondrial $F_{1}$-ATPase in yeast. J Biol Chem 271, 4887-4894.

100. Ackerman SH, and Tzagoloff A. (1990) Identification of two nuclear genes (ATP11, ATP12) required for assembly of the yeast $F_{1}$ ATPase. Proc Natl Acad Sci USA 87, 4986-4990.

101. Wang ZG, and Ackerman SH. (1998) Mutational studies with Atp12p, a protein required for assembly of the mitochondrial $F_{1-}$ ATPase in yeast - Identification of domains important for Atp12p function and oligomerization. J Biol Chem 273, 2993-3002.

102. Xiao Y, Metzl M, and Mueller DM. (2000) Partial uncoupling of the mitochondrial membrane by a heterozygous null mutation in the gene encoding the g- or d-subunit of the yeast mitochondrial ATPase. $J$ Biol Chem 275, 6963-6968.

103. Duvezin-Caubet S, Caron M, Giraud MF, Velours J, and di Rago JP. (2003) The two rotor components of yeast mitochondrial ATP synthase are mechanically coupled by subunit d. Proc Natl Acad Sci USA $100,13235-13240$

104. Mueller DM. (2000) Partial assembly of the yeast ATP synthase. J Bioener Biomem 32, 391-400.

105. Beasley EM, Wachter C, and Schatz G. (1992) Putting energy into mitochondrial protein import. Curr Opin Cell Biol 4, 646-651.

106. Gasser SM, Daum G, and Schatz G. (1982) Import of proteins into mitochondria. Energy-dependent uptake of precursors by isolated mitochondria. J Biol Chem 257, 13034-13041.

107. Klingenberg $M$, and Rottenberg $H$. (1977) Relation between the gradient of the ATP/ADP ratio and the membrane potential across the mitochondrial membrane. Eur J Biochem 73, 125-130.

108. Dupont CH, Mazat JP, and Guerin B. (1985) The role of adenine nucleotide translocation in the energization of the inner membrane of mitochondria isolated from $\mathrm{r}^{+}$and $\mathrm{r}^{0}$ strains of Saccharomyces cerevisiae. Biochem Biophys Res Commun 132, 1116-1123.

109. Kominsky DJ, Brownson MP, Updike DL, and Thorsness PE. (2002) Genetic and biochemical basis for viability of yeast lacking mitochondrial genomes. Genetics 162, 1595-1604.
110. Lai-Zhang J, and Mueller DM. (2000) Complementation of deletion mutants in the genes encoding the $\mathrm{F}_{1}$-ATPase by expression of the corresponding bovine subunits in yeast $S$. cerevisiae. Eur Biochem 267, 2409-2418.

111. Guélin E, Chevallier J, Rigoulet M, Guérin B, and Velours J. (1993) ATP synthase of yeast mitochondria. Isolation and disruption of the ATPe gene. J Biol Chem 268, 161-167.

112. Tetaud E, Godard F, Giraud MF, Ackerman SH, and di Rago JP. (2014) The depletion of $F_{1}$ subunit $e$ in yeast leads to an uncoupled respiratory phenotype that is rescued by mutations in the protontranslocating subunits of $F_{0}$. Mol Biol Cell 25, 791-799.

113. Clark-Walker GD, and Chen XJ. (1996) A vital function for mitochondrial DNA in the petite-negative yeast Kluyveromyces lactis. Mol Gen Genet 252, 746-750.

114. Chen XJ, Hansbro PM, and Clark-Walker GD. (1998) Suppression of rho lethality by mitochondrial ATP synthase $F_{1}$ mutations in Kluyveromyces lactis occurs in the absence of $F_{0}$. Mol Gen Genet 259, 457-467.

115. Hansbro PM, Chen XJ, and Clark-Walker GD. (1998) Allele specific expression of the mgi phenotype on disruption of the $F_{1}$-ATPase $d$ subunit gene in Kluyveromyces lactis. Curr Genet 33, 46-51.

116. Chen XJ, and Clark-Walker GD. (1999) a and b subunits of $F_{1-}$ ATPase are required for survival of petite mutants in Saccharomyces cerevisiae. Mol Gen Genet 262, 898-908.

117. Clark-Walker GD, Hansbro PM, Gibson F, and Chen XJ. (2000) Mutant residues suppressing rho $^{\circ}$-lethality in Kluyveromyces lactis occur at contact sites between subunits of $F_{1}$-ATPase. Biochim Biophys Acta 1478, 125-137.

118. Fernet CS, Clark-Walker GD, and Claisse ML. (2002) The mitochondrial genome can be altered or lost without lethal effect in the petite-negative yeast Debaryomyces (Schwanniomyces) occidentalis. Curr Genet 42, 94-102.

119. Kominsky DJ, and Thorsness PE. (2000) Expression of the Saccharomyces cerevisiae gene YME1 in the petite-negative yeast Schizosaccharomyces pombe converts it to petite-positive. Genetics $154,147-154$

120. Weber ER, Rooks RS, Shafer KS, Chase JW, and Thorsness PE. (1995) Mutations in the mitochondrial ATP synthase $g$ subunit suppress a slow-growth phenotype of yme1 yeast lacking mitochondrial DNA. Genetics 140, 435-442.

121. Schnaufer A, Clark-Walker GD, Steinberg AG, and Stuart K. (2005) The $F_{1}$-ATP synthase complex in bloodstream stage trypanosomes has an unusual and essential function. EMBO J 24, 4029-4040.

122. Dean S, Gould MK, Dewar CE, and Schnaufer AC. (2013) Single point mutations in ATP synthase compensate for mitochondrial genome loss in trypanosomes. Proc Natl Acad Sci USA 110, 1474114746.

123. Wang $Y$, Singh $U$, and Mueller DM. (2007) Mitochondrial genome integrity mutations uncouple the yeast Saccharomyces cerevisiae ATP synthase. J Biol Chem 282, 8228-8236.

124. Arsenieva D, Symersky J, Wang Y, Pagadala V, and Mueller DM. (2010) Crystal structures of mutant forms of the yeast $F_{1}$ ATPase reveal two modes of uncoupling. J Biol Chem 285, 36561-36569.

125. Gumbiowski K, Cherepanov D, Muller M, Panke O, Promto $P$, Winkler S, Junge W, and Engelbrecht S. (2001) F-ATPase: forced full rotation of the rotor despite covalent cross-link with the stator. J Biol Chem 276, 42287-42292.

126. Muller M, Gumbiowski K, Cherepanov DA, Winkler S, Junge W, Engelbrecht S, and Panke O. (2004) Rotary F1-ATPase. Is the Cterminus of subunit g fixed or mobile? Eur J Biochem 271, 3914-3922. 
127. Hilbers F, Junge $W$, and Sielaff $H$. (2013) The torque of rotary FATPase can unfold subunit $g$ if rotor and stator are cross-linked. PLoS One 8, e53754.

128. Ichida M, Endo H, Ikeda U, Matsuda C, Ueno E, Shimada K, and Kagawa Y. (1998) MyoD is indispensable for muscle-specific alternative splicing in mouse mitochondrial ATP synthase g-subunit pre-mRNA. J Biol Chem 273, 8492-8501.

129. Endo H, Matsuda C, and Kagawa Y. (1994) Exclusion of an alternatively spliced exon in human ATP synthase g-subunit pre-mRNA requires de novo protein synthesis. J Biol Chem 269, 12488-12493.

130. Hayakawa M, Endo H, Hamamoto $T$, and Kagawa Y. (1998) Acidic stimulation induces a negative regulatory factor that affects alternative exon selection in vitro in human ATP synthase g-subunit pre-mRNA. Biochem Biophys Res Commun. 251, 603-608.

131. Hayakawa M, Sakashita E, Ueno E, Tominaga S, Hamamoto T, Kagawa $Y$, and Endo H. (2002) Muscle-specific exonic splicing silencer for exon exclusion in human ATP synthase g-subunit pre-mRNA. J Biol Chem 277, 6974-6984.

132. Matsuda C, Endo $H$, Hirata $H$, Morosawa $H$, Nakanishi $M$, and Kagawa Y. (1993) Tissue-specific isoforms of the bovine mitochondrial ATP synthase g-subunit. FEBS Lett. 325, 281-284

133. Matsuda C, Muneyuki E, Endo $H$, Yoshida $M$, and Kagawa $Y$. (1994) Comparison of the ATPase activities of bovine heart and liver mitochondrial ATP synthases with different tissue-specific $g$ subunit isoforms. Biochem Biophys Res Commun 200, 671-678.

134. Rosen BP. (1973) Restoration of active transport in an $\mathrm{Mg}^{2+}$ adenosine triphosphatase- deficient mutant of Escherichia coli. J Bacteriol 116, 1124-1129.

135. Kanazawa H, Hama M, Rosen BP, and Futai M. (1985) Deletion of seven amino acid residues from the $\mathrm{g}$ subunit of Escherichia coli $\mathrm{H}^{+}$ATPase causes total loss of $F_{1}$ assembly on membranes. Arch Biochem Biophys 241, 364-370.

136. Furuike S, Hossain MD, Maki Y, Adachi K, Suzuki T, Kohori A, Itoh $H$, Yoshida M, and Kinosita K, Jr. (2008) Axle-less $F_{1}$-ATPase rotates in the correct direction. Science 319, 955-958.

137. Mnatsakanyan N, Hook JA, Quisenberry L, and Weber J. (2009) ATP synthase with its $g$ subunit reduced to the $\mathrm{N}$-terminal helix can still catalyze ATP synthesis. J Biol Chem 284, 26519-26525.

138. Hossain MD, Furuike S, Maki Y, Adachi K, Suzuki T, Kohori A, Itoh $\mathrm{H}$, Yoshida M, and Kinosita K, Jr. (2008) Neither helix in the coiled coil region of the axle of $F_{1}$-ATPase plays a significant role in torque production. Biophys J 95, 4837-4844.

139. Hossain MD, Furuike S, Maki Y, Adachi K, Ali MY, Huq M, Itoh $\mathrm{H}_{\text {, }}$ Yoshida M, and Kinosita K, Jr. (2006) The rotor tip inside a bearing of a thermophilic $F_{1}$-ATPase is dispensable for torque generation. Biophys J 90, 4195-4203.

140. Usukura E, Suzuki T, Furuike S, Soga N, Saita E, Hisabori T, Kinosita K, Jr., and Yoshida M. (2012) Torque generation and utilization in motor enzyme $F_{0} F_{1}$-ATP synthase: half-torque $F_{1}$ with short-sized pushrod helix and reduced ATP Synthesis by half-torque $\mathrm{F}_{0} \mathrm{~F}_{1}$. J Biol Chem 287, 1884-1891.

141. Mayr JA, Havlickova V, Zimmermann F, Magler I, Kaplanova V Jesina P, Pecinova A, Nuskova H, Koch J, Sperl W, and Houstek J. (2010) Mitochondrial ATP synthase deficiency due to a mutation in the ATP5E gene for the $F_{1}$ e subunit. Hum Mol Genet 19, 3430-3439.

142. Lieber DS, Calvo SE, Slate NG, Liu S, Hershman SG, Gold NB, Borowsky ML, Thorburn DR, Berry GT, Schmahmann JD, Mueller DM, Sims KB, and Mootha VK. (2013) Targeted exome sequencing of suspected mitochondrial disorders. Neurology 80, 1762-1770.
143. Jonckheere $A l$, Renkema $G H$, Bras $M$, van den Heuvel $L P$, Hoischen A, Gilissen C, Nabuurs SB, Huynen MA, de Vries MC, Smeitink JA, and Rodenburg RJ. (2013) A complex V ATP5A1 defect causes fatal neonatal mitochondrial encephalopathy. Brain 136, 15441554.

144. Holt IJ, Harding AE, Petty RK, and Morgan-Hughes JA. (1990) A new mitochondrial disease associated with mitochondrial DNA heteroplasmy. Am J Hum Genet 46, 428-433. PMID: 2137962.

145. Vik SB, and Ishmukhametov RR. (2005) Structure and function of subunit a of the ATP synthase of Escherichia coli. J Bioenerg Biomembr 37, 445-449.

146. DeLeon-Rangel J, Ishmukhametov RR, Jiang W, Fillingame RH, and Vik SB. (2013) Interactions between subunits $a$ and $b$ in the rotary ATP synthase as determined by cross-linking, FEBS Lett 587, 892-897.

147. Long JC, DeLeon-Rangel J, and Vik SB. (2002) Characterization of the first cytoplasmic loop of subunit a of the Escherichia coli ATP synthase by surface labeling, cross-linking, and mutagenesis. J Biol Chem 277, 27288-27293.

148. Moore KJ, and Fillingame RH. (2008) Structural interactions between transmembrane helices 4 and 5 of subunit a and the subunit c ring of Escherichia coli ATP synthase. J Biol Chem 283, 31726-31735.

149. Velours J, Paumard P, Soubannier V, Spannagel C, Vaillier J, Arselin G, and Graves PV. (2000) Organisation of the yeast ATP synthase $F_{0}$ : a study based on cysteine mutants, thiol modification and cross-linking reagents. Biochim Biophys Acta 1458, 443-456.

150. Angevine CM, Herold KA, Vincent OD, and Fillingame RH. (2007) Aqueous access pathways in ATP synthase subunit a. Reactivity of cysteine substituted into transmembrane helices 1, 3, and 5, J Biol Chem 282, 9001-9007.

151. Moslemi AR, Darin N, Tulinius M, Oldfors A, and Holme E. (2005) Two new mutations in the MTATP6 gene associated with Leigh syndrome, Neuropediatrics 36, 314-318.

152. Childs AM, Hutchin T, Pysden K, Highet L, Bamford J, Livingston J, and Crow YJ. (2007) Variable phenotype including Leigh syndrome with a 9185T>C mutation in the MTATP6 gene. Neuropediatrics 38, 313-316.

153. Castagna AE, Addis J, Mclnnes RR, Clarke JT, Ashby P, Blaser S, and Robinson $\mathrm{BH}$. (2007) Late onset Leigh syndrome and ataxia due to a $\mathrm{T}$ to $\mathrm{C}$ mutation at bp 9,185 of mitochondrial DNA. Am J Med Genet A $143 \mathrm{~A}, 808-816$

154. Verity CM, Winstone AM, Stellitano L, Krishnakumar D, Will R, and McFarland R. (2010) The clinical presentation of mitochondrial diseases in children with progressive intellectual and neurological deterioration: a national, prospective, population-based study. Dev Med Child Neurol 52, 434-440.

155. Gigarel N, Hesters L, Samuels DC, Monnot S, Burlet P, Kerbrat V, Lamazou F, Benachi A, Frydman R, Feingold J, Rotig A, Munnich A, Bonnefont JP, Frydman N, and Steffann J. (2011) Poor correlations in the levels of pathogenic mitochondrial DNA mutations in polar bodies versus oocytes and blastomeres in humans. Am J Hum Genet 88, 494 498.

156. Pereira L, Soares P, Radivojac P, Li B, and Samuels DC. (2011) Comparing phylogeny and the predicted pathogenicity of protein variations reveals equal purifying selection across the global human mtDNA diversity. Am J Hum Genet 88, 433-439.

157. Pfeffer G, Blakely EL, Alston CL, Hassani A, Boggild M, Horvath R, Samuels DC, Taylor RW, and Chinnery PF. (2012) Adult-onset spinocerebellar ataxia syndromes due to MTATP6 mutations. J Neurol Neurosurg Psychiatry 83, 883-886. 
158. Aure K, Dubourg O, Jardel C, Clarysse L, Sternberg D, Fournier E, Laforet $P$, Streichenberger N, Petiot $P$, Gervais-Bernard $H$, Vial $C$, Bedat-Millet AL, Drouin-Garraud V, Bouillaud F, Vandier C, Fontaine B, and Lombes A. (2013) Episodic weakness due to mitochondrial DNA MT-ATP6/8 mutations. Neurology 81, 1810-1818.

159. Saneto RP, and Singh KK. (2010) Illness-induced exacerbation of Leigh syndrome in a patient with the MTATP6 mutation, m.9185 T>C. Mitochondrion 10, 567-572.

160. Carrozzo R, Murray J, Capuano O, Tessa A, Chichierchia G, Neglia MR, Capaldi RA, and Santorelli FM. (2000) A novel mtDNA mutation in the ATPase6 gene studied by E. coli modeling. Neurol Sci 21, S983-984.

161. Carrozzo R, Murray J, Santorelli FM, and Capaldi RA. (2000) The T9176G mutation of human mtDNA gives a fully assembled but inactive ATP synthase when modeled in Escherichia coli. FEBS Lett 486 297-299.

162. Alvarez-Iglesias V, Barros F, Carracedo A, and Salas A. (2008) Minisequencing mitochondrial DNA pathogenic mutations. BMC Med Genet 9, 26.

163. Thyagarajan $D$, Shanske S, Vazquez-Memije M, De Vivo D, and DiMauro S. (1995) A novel mitochondrial ATPase 6 point mutation in familial bilateral striatal necrosis. Ann Neurol 38, 468-472.

164. Campos Y, Martin MA, Rubio JC, Solana LG, Garcia-Benayas C, Terradas JL, and Arenas J. (1997) Leigh syndrome associated with the T9176C mutation in the ATPase 6 gene of mitochondrial DNA. Neurology 49, 595-597.

165. Dionisi-Vici C, Seneca S, Zeviani M, Fariello G, Rimoldi M, Bertin E, and De Meirleir L. (1998) Fulminant Leigh syndrome and sudden unexpected death in a family with the T9176C mutation of the mitochondrial ATPase 6 gene. J Inherit Metab Dis 21, 2-8.

166. Makino M, Horai S, Goto Y, and Nonaka I. (1998) Confirmation that a T-to-C mutation at 9176 in mitochondrial DNA is an additiona candidate mutation for Leigh's syndrome. Neuromuscul Disord 8, 149-

167. Rubio-Gozalbo ME, Dijkman KP, van den Heuvel LP, Sengers RC, Wendel U, and Smeitink JA. (2000) Clinical differences in patients with mitochondriocytopathies due to nuclear versus mitochondrial DNA mutations. Hum Mutat 15, 522-532.

168. Mishmar D, and Zhidkov I. (2010) Evolution and disease converge in the mitochondrion. Biochim Biophys Acta 1797, 1099-1104.

169. Nakano K, Ohsawa I, Yamagata K, Nakayama T, Sasaki K, Tarashima M, Saito K, Osawa M, and Ohta S. (2003) Continuous culture of novel mitochondrial cells lacking nuclei. Mitochondrion 3 21-27.

170. Dobrowolski SF, Hendrickx AT, van den Bosch BJ, Smeets HJ, Gray J, Miller T, and Sears M. (2009) Identifying sequence variants in the human mitochondrial genome using high-resolution melt (HRM) profiling. Hum Mutat 30, 891-898.

171. Nishigaki Y, Ueno H, Coku J, Koga Y, Fujii T, Sahashi K, Nakano K, Yoneda M, Nonaka M, Tang L, Liou CW, Paquis-Flucklinger V, Harigaya Y, Ibi T, Goto Y, Hosoya H, DiMauro S, Hirano M, and Tanaka M. (2010) Extensive screening system using suspension array technology to detect mitochondrial DNA point mutations. Mitochondrion 10, 300308

172. Kucharczyk R, Ezkurdia N, Couplan E, Procaccio V, Ackerman SH, Blondel $\mathrm{M}$, and di Rago JP. (2010) Consequences of the pathogenic T9176C mutation of human mitochondrial DNA on yeast mitochondrial ATP synthase. Biochim Biophys Acta 1797, 1105-1112.
173. Shidara Y, Yamagata K, Kanamori T, Nakano K, Kwong JQ, Manfredi G, Oda H, and Ohta S. (2005) Positive contribution of pathogenic mutations in the mitochondrial genome to the promotion of cancer by prevention from apoptosis. Cancer Res 65, 1655-1663.

174. Verny C, Guegen N, Desquiret V, Chevrollier A, Prundean A, Dubas F, Cassereau J, Ferre M, Amati-Bonneau P, Bonneau D, Reynier $P$, and Procaccio V. (2011) Hereditary spastic paraplegia-like disorder due to a mitochondrial ATP6 gene point mutation. Mitochondrion 11, 70-75.

175. Ronchi D, Bordoni A, Cosi A, Rizzuti M, Fassone E, Di Fonzo A, Servida M, Sciacco M, Collotta M, Ronzoni M, Lucchini V, Mattioli M, Moggio M, Bresolin N, Corti S, and Comi GP. (2011) Unusual adultonset Leigh syndrome presentation due to the mitochondrial m.9176T>C mutation. Biochem Biophys Res Commun 412, 245-248.

176. Ciafaloni E, Santorelli FM, Shanske S, Deonna T, Roulet E, Janzer C, Pescia G, and DiMauro S. (1993) Maternally inherited Leigh syndrome. J Pediatr 122, 419-422.

177. Vazquez-Memije ME, Shanske S, Santorelli FM, Kranz-Eble $P$, DeVivo DC, and DiMauro S. (1998) Comparative biochemical studies of ATPases in cells from patients with the T8993G or T8993C mitochondrial DNA mutations. J Inherit Metab Dis 21, 829-836.

178. de Vries DD, van Engelen BG, Gabreels FJ, Ruitenbeek W, and van Oost BA. (1993) A second missense mutation in the mitochondrial ATPase 6 gene in Leigh's syndrome. Ann Neurol 34, 410-412.

179. Santorelli FM, Shanske S, Jain KD, Tick D, Schon EA, and DiMauro S. (1994) A T-->C mutation at nt 8993 of mitochondrial DNA in a child with Leigh syndrome. Neurology 44, 972-974.

180. Pallotti F, Baracca A, Hernandez-Rosa E, Walker WF, Solaini G, Lenaz G, Melzi D'Eril GV, Dimauro S, Schon EA, and Davidson MM. (2004) Biochemical analysis of respiratory function in cybrid cell lines harbouring mitochondrial DNA mutations. Biochem J 384, 287-293.

181. Morava $E$, Rodenburg RJ, Hol F, de Vries $M$, Janssen A, van den Heuvel L, Nijtmans L, and Smeitink J. (2006) Clinical and biochemical characteristics in patients with a high mutant load of the mitochondrial T8993G/C mutations. Am J Med Genet A 140, 863-868.

182. Rantamaki MT, Soini HK, Finnila SM, Majamaa K, and Udd B. (2005) Adult-onset ataxia and polyneuropathy caused by mitochondrial 8993T-->C mutation. Ann Neurol 58, 337-340.

183. Harding AE, Holt IJ, Sweeney MG, Brockington M, and Davis MB (1992) Prenatal diagnosis of mitochondrial DNA8993 T----G disease. Am J Hum Genet 50, 629-633.

184. Pastores GM, Santorelli FM, Shanske S, Gelb BD, Fyfe B, Wolfe D, and Willner JP. (1994) Leigh syndrome and hypertrophic cardiomyopathy in an infant with a mitochondrial DNA point mutation (T8993G). Am J Med Genet 50, 265-271.

185. Santorelli FM, Shanske S, Macaya A, DeVivo DC, and DiMauro S. (1993) The mutation at nt 8993 of mitochondrial DNA is a common cause of Leigh's syndrome. Ann Neurol 34, 827-834.

186. Shoffner JM, Fernhoff PM, Krawiecki NS, Caplan DB, Holt PJ, Koontz DA, Takei Y, Newman NJ, Ortiz RG, Polak M, and et al. (1992) Subacute necrotizing encephalopathy: oxidative phosphorylation defects and the ATPase 6 point mutation. Neurology 42, 2168-2174.

187. Sgarbi G, Baracca A, Lenaz G, Valentino LM, Carelli V, and Solaini G. (2006) Inefficient coupling between proton transport and ATP synthesis may be the pathogenic mechanism for NARP and Leigh syndrome resulting from the T8993G mutation in mtDNA. Biochem J $395,493-500$. 
188. Baracca A, Sgarbi G, Mattiazzi M, Casalena G, Pagnotta E, Valentino ML, Moggio M, Lenaz G, Carelli V, and Solaini G. (2007) Biochemical phenotypes associated with the mitochondrial ATP6 gene mutations at nt8993. Biochim Biophys Acta 1767, 913-919.

189. Mak SC, Chi CS, Liu CY, Pang CY, and Wei YH. (1996) Leigh syndrome associated with mitochondrial DNA 8993 T-->G mutation and ragged-red fibers. Pediatr Neurol 15, 72-75.

190. Schon EA, Santra S, Pallotti F, and Girvin ME. (2001) Pathogenesis of primary defects in mitochondrial ATP synthesis. Semin Cell Dev Biol $12,441-448$.

191. Kucharczyk R, Zick M, Bietenhader M, Rak M, Couplan E, Blondel M, Caubet SD, and di Rago JP. (2009) Mitochondrial ATP synthase disorders: molecular mechanisms and the quest for curative therapeutic approaches. Biochim Biophys Acta 1793, 186-199.

192. Houstek J, Mracek T, Vojtiskova A, and Zeman J. (2004) Mitochondrial diseases and ATPase defects of nuclear origin. Biochim Biophys Acta 1658, 115-121.

193. Rak M, Tetaud E, Godard F, Sagot I, Salin B, Duvezin-Caubet S, Slonimski PP, Rytka J, and di Rago JP. (2007) Yeast cells lacking the mitochondrial gene encoding the ATP synthase subunit 6 exhibit a selective loss of complex IV and unusual mitochondrial morphology. J Biol Chem 282, 10853-10864.

194. Soto IC, Fontanesi F, Valledor M, Horn D, Singh R, and Barrientos A. (2009) Synthesis of cytochrome $c$ oxidase subunit 1 is translationally downregulated in the absence of functional $F_{1} F_{0}$-ATP synthase. Biochim Biophys Acta 1793, 1776-1786.

195. Hartzog PE, and Cain BD. (1993) The $a_{\text {leu207-->arg }}$ mutation in $\mathrm{F}_{1} \mathrm{~F}_{0^{-}}$ ATP synthase from Escherichia coli. A model for human mitochondrial disease. J Biol Chem 268, 12250-12252. PMID:8509361

196. Cortes-Hernandez P, Vazquez-Memije ME, and Garcia JJ. (2007) ATP6 homoplasmic mutations inhibit and destabilize the human $F_{1} F_{0^{-}}$ ATP synthase without preventing enzyme assembly and oligomerization. J Biol Chem 282, 1051-1058.
197. Kucharczyk R, Rak M, and di Rago JP. (2009) Biochemical consequences in yeast of the human mitochondrial DNA 8993T $>C$ mutation in the ATPase6 gene found in NARP/MILS patients. Biochim Biophys Acta 1793, 817-824.

198. Rak M, Tetaud E, Duvezin-Caubet S, Ezkurdia N, Bietenhader M, Rytka J, and di Rago JP. (2007) A yeast model of the neurogenic ataxia retinitis pigmentosa (NARP) T8993G mutation in the mitochondrial ATP synthase-6 gene. J Biol Chem 282, 34039-34047.

199. Jonckheere Al, Hogeveen M, Nijtmans LG, van den Brand MA, Janssen AJ, Diepstra JH, van den Brandt FC, van den Heuvel LP, Hol FA, Hofste TG, Kapusta L, Dillmann U, Shamdeen MG, Smeitink JA, and Rodenburg RJ. (2008) A novel mitochondrial ATP8 gene mutation in a patient with apical hypertrophic cardiomyopathy and neuropathy. J Med Genet 45, 129-133.

200. Ware SM, El-Hassan N, Kahler SG, Zhang Q, Ma YW, Miller E, Wong B, Spicer RL, Craigen WJ, Kozel BA, Grange DK, and Wong LJ. (2009) Infantile cardiomyopathy caused by a mutation in the overlapping region of mitochondrial ATPase 6 and 8 genes. J Med Genet 46, 308-314.

201. Ketchum CJ, Al-Shawi MK, and Nakamoto RK. (1998) Intergenic suppression of the gM23K uncoupling mutation in $\mathrm{F}_{0} \mathrm{~F}_{1}$ ATP synthase by bGlu-381 substitutions: the role of the $b^{380}$ DELSEED $^{386}$ segment in energy coupling. Biochem J 330, 707-712.

202. Al-Shawi MK, and Nakamoto RK. (1997) Mechanism of energy coupling in the $\mathrm{F}_{0} \mathrm{~F}_{1}$-ATP synthase: The uncoupling mutation, gM23K, disrupts the use of binding energy to drive catalysis. Biochemistry 36 , 12954-12960.

203. Al-Shawi MK, Ketchum CJ, and Nakamoto RK. (1997) The Escherichia coli $\mathrm{F}_{0} \mathrm{~F}_{1}$ gM23K uncoupling mutant has a higher $\mathrm{K}_{0.5}$ for $\mathrm{P}_{\mathrm{i}}$. Transition state analysis of this mutant and others reveals that synthesis and hydrolysis utilize the same kinetic pathway. Biochemistry 36, 12961-12969.

204. Steed PR, and Fillingame RH. (2009) Aqueous accessibility to the transmembrane regions of subunit $\mathrm{c}$ of the Escherichia coli $\mathrm{F}_{1} \mathrm{~F}_{0}$ ATP synthase. J Biol Chem 284, 23243-23250. 